\title{
LOBBY GROUPS AND THE FINANCIAL SUPPORT OF ELECTION CAMPAIGNS*
}

\author{
M. Socorro Puy**
}

WP-AD 99-18

Correspondence to: M. Socorro Puy, Departamento de Fundamentos del Análisis Económico, Universidad de Alicante. Alicante, 03071 Spain.E-mail: mps@uma.es

Editor: Instituto Valenciano de Investigaciones Económicas, S.A.

First Edition October 1999

Depósito Legal: V-4231-1999

IVIE working papers offer in advance the results of economic research under way in order to encourage a discussion process before sending them to scientific journals for their final publication.

* The author thanks Ignacio Ortuño-Ortín for his guidance in writing this paper and also Pablo Amorós, Enriqueta Aragonés, Jean-Marie Baland, Elhanan Helpman, Carmen Herrero, Annick Laruelle, François Maniquet, Jim Robinson, Francisco Rodriguez, Christian Schultz and the seminar audience of Alicante and that of the Asset Meeting for their comments. The author gratefully acknowledges financial support from the "Gobierno de Navarra" and the IVIE.

** M.S. Puy: University of Alicante. 


\title{
LOBBY GROUPS AND THE FINANCIAL SUPPORT OF ELECTION CAMPAIGNS
}

\author{
M. Socorro Puy
}

\begin{abstract}
We study a model of competition between two political parties with policy compromise. There is a special interest group with well-defined preferences on political issues. Voters are of two kinds: impressionable and knowledgeable. The impressionable voters are influenced by the election campaigns. The objective of the parties is to obtain the maximum votes.Parties compete for financial support from a given interest group. Each party proposes a platform in exchange for an amount of campaign funds, and the interest group decides whether to accept or reject each of these proposals. We show that parties competition resembles, to a certain extent, Bertrand competition. Furthermore, in equilibrium only one party gets funds from the interest group. This result differs from the one obtained in a similar model by Grossman and Helpman (1996a) (1996b), in which, in equilibrium, both parties are financed by the interest group. This difference arises because Grossman and Helpman assume that it is the interest group who makes the proposals to the political parties.
\end{abstract}

Keywords: Contract proposal; Lobby groups; Policy compromise; Bertrand competition. 


\section{Introduction}

Without doubt, the campaign funding is becoming an important political issue for public opinion, not only because political parties are handling large sums of money, but also because the funds for the political campaigns are often obtained in exchange for different kinds of favors and political concessions. For instance, it is well known that the tobacco companies are among the most important donors to election campaigns in the U.S..

With regard to this exchange, some authors refer to political campaigns as a kind of market where the "goods" supplied by politicians are certain policies (regulation, transfers, public goods, etc.), the interest groups are the "demanders" and the "price" of the good is the amount of campaign contribution. With this in mind, in this paper we address the following questions: is there any similarity between market competition and the competition established among political parties in order to obtain additional votes?, and to what extent the process of negotiation between the parties and the interest groups favors competition?

Grossman and Helpman (1996a) and (1996b) (G-H in the sequel), introduce a two-political party model with an only interest group. They suggest that the interest group offers the parties a contract proposal that stipulates a fixed sum as a campaign contribution for each policy and which the parties are free to accept or reject. They base their proposal on the literature on "common agency" (see Bernheim and Whinston (1986), Grossman and Helpman (1994)), which suggest that the "principal" is the interest group which is directly affected by the action taken by the government, who is then, the "agent". Hence, when the agent chooses an option, the principal makes the corresponding payment.

In this paper, we suggest an alternative negotiation process between the parties and the interest group. In our approach the political parties are the ones who initiate the negotiation. We change the direction of negotiation assuming that it is the parties who make the proposals to the interest group. We consider that each party, simultaneously, proposes a contract to the interest group which consists of a policy together with a fixed campaign contribution sum. The interest group then, decides which proposals it accepts.

Our negotiation proposal is not based on a "principal-agent" argument. What we wish to emphasize is that when the parties are faced with close election race, their incentive to obtain financial support for a powerful political campaign increases. We therefore suggest, that the competition among parties to win elections is closely related to the sort of competition that they face in obtaining greater 
financial support from a financially powerful interest group. Thus, parties compete in such a way that they try to offer the objective of the interest group at a minimum cost (in terms of campaign contribution). We find that, in equilibrium, both parties offer to the interest group its objective and they also request the same amount of campaign contribution. Hence, the interest group is indifferent between financing one or the other party. However, in both cases, the more popular party benefits in terms of votes. As we shall show, with our proposal of negotiation, the competition between the two political parties resembles, to a certain extent, Bertrand competition.

Comparing our results to those obtained by G-H, we observe that the main difference consists of whether the interest group provides funding for the political campaign of one or both of the parties. Indeed, G-H obtain that the interest group always finances both parties, whereas we obtain that only one party is financed. These results are justified on the basis that in the empirical literature on campaign contributions, there is evidence for both conjectures, that of financing only one party ${ }^{1}$ and that of financing both ${ }^{2}$ (see Potters and Sloof (1996) for a further discussion on these empirical results). Furthermore, with our approach, the election results always shift in favor of the most popular party, whereas G-H obtain that, in general, the results of the elections are not affected.

We deduce then, that on the one hand, from the point of view of the parties, only the most popular party benefits from initiating the negotiations. And on the other hand, from the point of view of the interest group, it is more profitable to be the one that initiates the negotiations.

Let us next compare the implications of our results with additional literature on interest groups. As Potters and Winden (1995) point out, two competing theoretical models ${ }^{3}$ on campaign contributions can be identified:

The first type of models suggests that the interest group may contribute to the political campaigns of both parties. These models assume that the probability that a party be elected is fixed and that the party implements a policy which is more favorable to the interest group to the extent that the group has contributed to the party's campaign.

The second type of models suggest that the interest group always contributes to the campaign of one party. These results are based on the assumption that

\footnotetext{
${ }^{1}$ See for example Langbein (1993) and Poole and Romer (1985).

${ }^{2}$ See for example Schlozman and Tierney (1996).

${ }^{3}$ This division is also considered in Potters and Sloof (1995), there they survey the empirical studies that test both competing models.
} 
the interest group takes the policy positions of the parties as given and that the campaign contributions are aimed at influencing the election outcome. Hence, a group's contribution to a party increases according to the attractiveness of the party's platform.

The first type of model is criticized as it fails to explain why a party's policy changes in response to campaign contributions. The second type of model is also criticized since it suggests that the interest group can influence the behavior of the voters but not the behavior of the candidates.

Regarding the model introduced by $\mathrm{G}-\mathrm{H}$, we find that it avoids both criticisms since it considers neither the election results nor the parties' policies to be fixed. Moreover, their results are quite robust since the interest group finances both parties even when the voters perform strategically. However, we have found that G-H results are not robust to the alternative of reversing the direction of the campaign negotiation.

The paper is organized as follows: In section 2, we describe the model. In section 3 , we specify our negotiation proposal and introduce some restrictions on the model. In section 4, we show existence and uniqueness of a political equilibrium, and finally, in section 5, we discuss the similarities with Bertrand competition and we provide a comparison between our result and that of G-H.

\section{The Model}

The basic model we present is almost identical to the one described by $\mathrm{G}-\mathrm{H}^{4}$. We shall specify those assumptions that differ from G-H's model.

\section{The political issues:}

They consider that the parliament will be called upon to settle two political issues. One of these is the ideology denoted by $q$ and the other is a pliable issue denoted by $p$. By ideology they mean those political issues on which the parties usually maintain a firm position, which may well be inherited from the past. Examples of such a political issue are being left or right-wing or being a Democrat or a Republican.

The pliable issue consist of a political issue that may be more easily modified. Such an issue is independent of ideology and is such that the parties do not have a prior interest in it. Examples of this type of issue might be some form of regulation, transfers, public goods, etc.

\footnotetext{
${ }^{4}$ Grossman and Helpman (1996a) and (1996b)
} 


\section{The political parties:}

G-H consider two political parties denoted by $j \in\{A, B\}$. Each one has a different and well-defined ideology that is represented by $q_{j}$. In particular, the ideology is represented by the extreme points of the unit interval where $q_{A}=0$ and $q_{B}=1$. With regard to the pliable issue, each party has to decide which platform it is going to support during the election campaign. This platform is denoted by $p_{j}$ and it is an element of the interval $[0,1]$. The objective of the parties is to maximize the number of votes.

\section{The voting population and the elections:}

G-H consider a society with a continuum of voters. As in Baron (1994), the voters are divided into two groups, according to the attitudes they have towards the policy, i.e., the knowledgeable voters and the impressionable voters.

The impressionable voters are those who have no prior opinion about politics. They are susceptible to electioneering activities like campaign propaganda. Their vote does not depend on the policies supported by the parties, but rather on the political campaign that each party carries out. Thus, G-H assume that the percentage of impressionable votes that party A shall obtain is given by:

$$
\frac{1}{2}+b+h\left(c_{A}-c_{B}\right)
$$

where $b>0$ represents the ex ante popularity of party $A, c_{A}, c_{B} \in \mathbb{R}_{+}$are the amounts that each party spends on its political campaig $n^{5}$ and $h$ is a positive constant that indicates the effectiveness of the campaign funds.

The knowledgeable voters have well-defined preferences on the political issues. For a voter of type $i$, his preferences are as follows:

$$
u_{i}(p, q)=-a\left|p-\pi_{i}\right|+\beta_{i} q
$$

where $a$ is a strictly positive constant, $\pi_{i}$ is his ideal pliable policy and $\beta_{i}$ is the marginal utility that he derives from the ideology. It is assumed that $\pi_{i}$ and $\beta_{i}$ are independently and uniformly distributed in the intervals $[0,1]$ and $\left[-\frac{1}{2 f}-\frac{b}{f}, \frac{1}{2 f}-\frac{b}{f}\right]$ respectively ${ }^{6}$, where $f$ is a positive constant that represents the density of the distribution. Note that as $f$ increases, the diversity of views

\footnotetext{
${ }^{5}$ Note that it should be always the case that this percentage of votes does not excess from 1. This percentage can be also expressed as follows: $\min \left\{\frac{1}{2}+b+h\left(c_{A}-c_{B}\right), 1\right\}$. Since in equilibrium this percentage is smaller than 1 , for the sake of simplicity we do not consider this expression.

${ }^{6}$ This last interval has been specially chosen in order to facilitate the probability calculus.
} 
on the ideology decreases, in this case, there are more voters at the margin of indifference between the two parties.

Each knowledgeable voter votes sincerely, i.e., he supports the party whose ideology and platform on the pliable issue he prefers. Given a pair of platforms $p_{A}$ and $p_{B}$, he supports party $A$ when:

$$
u_{i}\left(p_{A}, 0\right) \geqslant u_{i}\left(p_{B}, 1\right) .
$$

Following G-H, from the joint density function we deduce that the percentage of knowledgeable voters who cast their ballot for party $\mathrm{A}$ is given by:

$$
\frac{1}{2}+b-f a\left(p_{A}-\frac{1}{2}\right)^{2}+f a\left(p_{B}-\frac{1}{2}\right)^{2} .
$$

$>$ From (2.1), we observe that as $f$ increases, i.e., as the diversity of views on the ideology is smaller, the knowledgeable voters are more sensible towards a movement of the platforms $p_{A}$ and $p_{B}$.

For all $j \in\{A, B\}$, let $s_{j}$ be the percentage of votes that party $j$ obtains in the elections. And let $\alpha$ be the percentage of impressionable voters and $(1-\alpha)$ the percentage of knowledgeable voters, so that

$$
s_{A}\left(c_{A}, p_{A}, c_{B}, p_{B}\right)=\frac{1}{2}+b-(1-\alpha) f a\left(\left(p_{A}-\frac{1}{2}\right)^{2}-\left(p_{B}-\frac{1}{2}\right)^{2}\right)+\alpha h\left(c_{A}-c_{B}\right)
$$

And consequently,

$$
s_{B}\left(c_{A}, p_{A}, c_{B}, p_{B}\right)=1-s_{A}\left(c_{A}, p_{A}, c_{B}, p_{B}\right) .
$$

G-H assume that the elections determine the composition of the legislature via proportional representation ${ }^{7}$. This implies that the implemented pliable policy is given $b^{8}$

$$
p\left(c_{A}, p_{A}, c_{B}, p_{B}\right)=p_{A} s_{A}\left(c_{A}, p_{A}, c_{B}, p_{B}\right)+p_{B} s_{B}\left(c_{A}, p_{A}, c_{B}, p_{B}\right)
$$

In the same way, since $q_{A}=0$ and $q_{B}=1$ the implemented ideology is given by

$$
q\left(c_{A}, p_{A}, c_{B}, p_{B}\right)=s_{B}\left(c_{A}, p_{A}, c_{B}, p_{B}\right) .
$$

\footnotetext{
${ }^{7}$ This last assumption offers a very novel point of view on political models. It questions many models written to date which assume that the policy finally adopted is that of the winning party. Similar assumptions are also introduced by Austen-Smith and Banks (1988), by Alesina and Rosenthal (1991) (1996), by Ortuño-Ortín (1997) and by Gerber and Ortuño-Ortín (1998).

${ }^{8}$ Instead of weighing the final policy with $s_{A}$, it can be assumed that the weight is given by a function $\Psi\left(s_{A}\right)$, where $\Psi(0)=0, \Psi^{\prime}\left(s_{A}\right) \geqslant 0$ for $\forall s_{A}$ and $\Psi^{\prime \prime}\left(s_{A}\right) \leqslant 0$ for $s_{A} \geqslant \frac{1}{2}$.
} 


\section{The interest group:}

G-H assume that there is only one lobby. It is formed by a small group of knowledgeable voters who have similar preferences on the pliable issue. In particular, it is composed of those voters whose ideal pliable policy $\pi_{i}$ belongs to a specific interval $\left[\pi_{1}, \pi_{2}\right]$. G-H assume that the preferences of the interest group are represented by the joint surplus of its members. However, we assume that the preferences of the interest group are represented by the following utility function:

$$
W\left(c_{A}, p_{A}, c_{B}, p_{B}\right)=-a\left|p\left(c_{A}, p_{A}, c_{B}, p_{B}\right)-\pi_{m}\right|-c_{A}-c_{B}
$$

where $c_{A}$ and $c_{B}$ are the contributions to the election campaign of each party and $\pi_{m}$ is a pliable policy decided by the members of the interest group ${ }^{9}$. It is important to point out that the results obtained by G-H also hold when this utility function is introduced in their analysis. We provide a proof of this claim in Appendix 6.1, where we also explain why this utility function rather than that proposed by G-H, facilitates our analysis.

In the sequel we consider the case of $\pi_{m}<\frac{1}{2}$. All the results obtained also hold when $\pi_{m}>\frac{1}{2}$. Solving the problem when $\pi_{m}=\frac{1}{2}$ is a trivial case, as we shall demonstrate in the following section.

\section{Campaign Negotiations.}

The objective of the parties is to maximize their number of votes, where the votes are given by expression ${ }^{10}(2.2)$. With this purpose they want to obtain financial support for their election campaigns. The campaign funds are the only way of obtaining additional votes from the impressionable voters. We assume that the interest group is the only institution that provides these funds. However, the interest group is only willing to provide funds when this is in exchange for obtaining a shift in the platform of the parties towards $\pi_{m}$.

\footnotetext{
${ }^{9}$ Notice that it is assumed that the ideology that is finally implemented do not play any role in the decision making process of the interest group.

$10>$ From expression (2.2), we can also interpret that the parties maximize weighted average of utility in society and contributions. And so, the greater effectiveness of the campaign funds $h$, and the greater the percentage of impressionable voters $\alpha$, the more weight is given to campaign contributions.
} 
Note that if a party receives no campaign contribution it is a dominant strategy to choose $p_{j}=\frac{1}{2}$. This follows directly from $(2.2)$.

We now introduce the crucial assumption that makes the negotiation different from that presented by G-H. While G-H assume that the interest group initiates the negotiation, we assume that the parties are the ones who initiate it. The timing of the negotiation process is as follows:

Firstly, both parties make a proposal to the interest group. A proposals is a pair $\left(c_{j}, p_{j}\right)$ that describes an amount of campaign contribution $c_{j}$ and a platform $p_{j}$. At the second stage, the interest group decides to accept one, both or neither of the proposals.

Finally, at the third stage, once a proposal has been accepted, the interest group contributes $c_{j}$ to the election campaign of party $j$, and this party commits itself to supporting the platform $p_{j}$. When a proposal is rejected, the party supports the platform $p_{j}=\frac{1}{2}$ (which is its dominant strategy) and it does not receive funds for its campaign.

In order to clarify the negotiation process, we introduce some definitions. Let us next define the proposals made by the parties to the interest group as follows

Definition 3.1. A contract proposal for party $j \in\{A, B\}$ is a pair $C_{j}=$ $\left(c_{j}, p_{j}\right)$ where $c_{j} \in \mathbb{R}_{+}, p_{j} \in[0,1]$.

Each $C_{j}$ is the announcement of an amount of campaign contribution ${ }^{11} c_{j}$ together with a platform $p_{j}$.

We denote by $\mathcal{C}$ the set of all the feasible contract proposals

$$
\mathcal{C}=\left\{\left(c_{j}, p_{j}\right): c_{j} \in \mathbb{R}_{+}, p_{j} \in[0,1]\right\}
$$

We shall denote by $C_{o} \in \mathcal{C}$, the pair $C_{o}=\left(0, \frac{1}{2}\right)$, that indicates that a party is not financed, i.e. $c_{j}=0$, and that it supports the platform $p_{j}=\frac{1}{2}$.

Once the contract proposals are communicated to the interest group, we formalize the decision made by the interest group as a contract resolution.

\footnotetext{
${ }^{11}$ For every $C_{j}=\left(c_{j}, p_{j}\right), c_{j}$ can be also interpreted as the minimal amount of campaign contribution required when the policy $p_{j}$ is offered by party $j$. If instead of considering a pair $C_{j}=\left(c_{j}, p_{j}\right)$, we consider that the proposals are functions, for instance let $f_{j}:[0,1] \longrightarrow \mathbb{R}_{+}$be a proposal where $f_{j}\left(p_{j}\right)=c_{j}$, our result also holds.
} 
Definition 3.2. A contract resolution for the contract proposals $C_{A}, C_{B} \in \mathcal{C}$ is given by the set

$$
\begin{aligned}
R\left(C_{A}, C_{B}\right)= & \arg \max W\left(C_{A}^{\prime}, C_{B}^{\prime}\right) \\
& \text { s.t. }\left(C_{A}^{\prime}, C_{B}^{\prime}\right) \in\left\{\begin{array}{c}
\left(C_{A}, C_{B}\right),\left(C_{A}, C_{o}\right) \\
\left(C_{o}, C_{B}\right),\left(C_{o}, C_{o}\right)
\end{array}\right\} .
\end{aligned}
$$

For each contract resolution, the percentage of votes that party $j$ obtains, is given by $s_{j}\left(R\left(C_{A}, C_{B}\right)\right)$. We assume that when a contract resolution contains more than one alternative, each of these alternatives is chosen with equal probability and then, parties maximize the expected percentage of votes.

In order to define what is an equilibrium in this negotiation process, let us next define what is a best response for each of the parties.

Definition 3.3. For $j \in\{A, B\}, C_{j}$ is a best response to $C_{k}$, if $s_{j}\left(R\left(C_{j}, C_{k}\right)\right) \geqslant$ $s_{j}\left(R\left(C_{j}^{\prime}, C_{k}\right)\right)$ for all $C_{j}^{\prime} \in \mathcal{C}$.

Definition 3.4. A political equilibrium is a pair of feasible contract proposals $\left(C_{A}, C_{B}\right) \in \mathcal{C}$ such that each one is a best response to the other party contract proposal.

We next introduce several definitions that are useful to calculate the political equilibria of the negotiation process.

In the following definition we describe pairs of contract proposals with the property of achieving the political objective of the interest group, $\pi_{m}$.

Definition 3.5. We say that a pair of contract proposals $C_{A}, C_{B} \in \mathcal{C}$ achieves policy $\pi_{m}$ if the implemented policy $p\left(C_{A}, C_{B}\right)=\pi_{m}$.

Note that the above definition is independent of the contract resolution. We next use this property to describe a contract proposal that we denote as the just-compensating contract.

Definition 3.6. We say that $\hat{C}_{j}=\left(\widehat{c}_{j}, \hat{p}_{j}\right)$ is the just-compensating contract for party $j$ if :

i) $p\left(\hat{C}_{j}, C_{o}\right)=\pi_{m}$ when $j=A,\left(p\left(C_{o}, \hat{C}_{j}\right)=\pi_{m}\right.$ when $\left.j=B\right)$.

ii) $s_{j}\left(\hat{C}_{j}, C_{o}\right)=\frac{1}{2}+b$ when $j=A$ (and $s_{j}\left(C_{o}, \hat{C}_{j}\right)=\frac{1}{2}-b$ when $j=B$ ). 
By ii), $\hat{C}_{j}$ is such that the relation between $\hat{c}_{j}$ and $\hat{p}_{j}$ indicates that the amount of campaign funds requested, $\widehat{c}_{j}$, just compensates (in terms of votes) the loss of votes due to supporting policy $\widehat{p}_{j}$. From the functions $s_{A}$ and $s_{B}$, we deduce that ii) holds when

$$
\hat{c}_{j}=\frac{(1-\alpha) f a}{\alpha h}\left(\hat{p}_{j}-\frac{1}{2}\right)^{2} \text { for } j \in\{A, B\} .
$$

The just-compensating contract for party $A$ gives the campaign contribution $\widehat{c}_{A}$ necessary for supporting a platform with which at the end $\pi_{m}$ is implemented. From the lobby point of view it would be just as good to give this contribution to the other party provided it would support a policy which also at the end would implement $\pi_{m}$. We call this policy the equivalent policy $\breve{p}_{B}$. Formally,

Definition 3.7. Let $\hat{C}_{A}=\left(\widehat{c}_{A}, \hat{p}_{A}\right) \in \mathcal{C}$ and $\hat{C}_{B}=\left(\widehat{c}_{B}, \hat{p}_{B}\right) \in \mathcal{C}$ be the justcompensating contracts for party $A$ and $B$ respectively. Then, we say that $\breve{p}_{A} \in$ $[0,1]$ is an equivalent policy for party $A$, if $p\left(\left(\hat{c}_{B}, \breve{p}_{A}\right), C_{o}\right)=\pi_{m}$. And $\breve{p}_{B} \in$ $[0,1]$ is an equivalent policy for party $B$, if $p\left(C_{o},\left(\hat{c}_{A}, \breve{p}_{B}\right)\right)=\pi_{m}$.

An important characteristic of the equivalent policies is the following,

$$
\begin{aligned}
W\left(C_{o},\left(\hat{c}_{A}, \breve{p}_{B}\right)\right) & =W\left(\hat{C}_{A}, C_{o}\right)=-\hat{c}_{A} \\
\text { and } W\left(\left(\hat{c}_{B}, \breve{p}_{A}\right), C_{o}\right) & =W\left(C_{o}, \hat{C}_{B}\right)=-\hat{c}_{B}
\end{aligned}
$$

In Figure 1, we represent the pairs $\left(c_{A}, p_{A}\right)$ fulfilling $p\left(C_{A}, C_{o}\right)=\pi_{m}$ and the pairs $\left(c_{B}, p_{B}\right)$ fulfilling $p\left(C_{o}, C_{B}\right)=\pi_{m}$. These functions ${ }^{12}$ contain all the feasible contract proposals that achieve policy $\pi_{m}$ when the other party takes the contract proposal $C_{o}$. Points $A$ and $B$ represent the just-compensating contracts for party $A$ and $B$ respectively. And points $A^{\prime}$ and $B^{\prime}$ are deduced from the equivalent policy $\breve{p}_{A}$ and $\breve{p}_{B}$.

\footnotetext{
${ }^{12}$ Under some assumptions that we next introduce it can be shown that the slopes of these functions are strictly positive and they do not cross each other.
} 


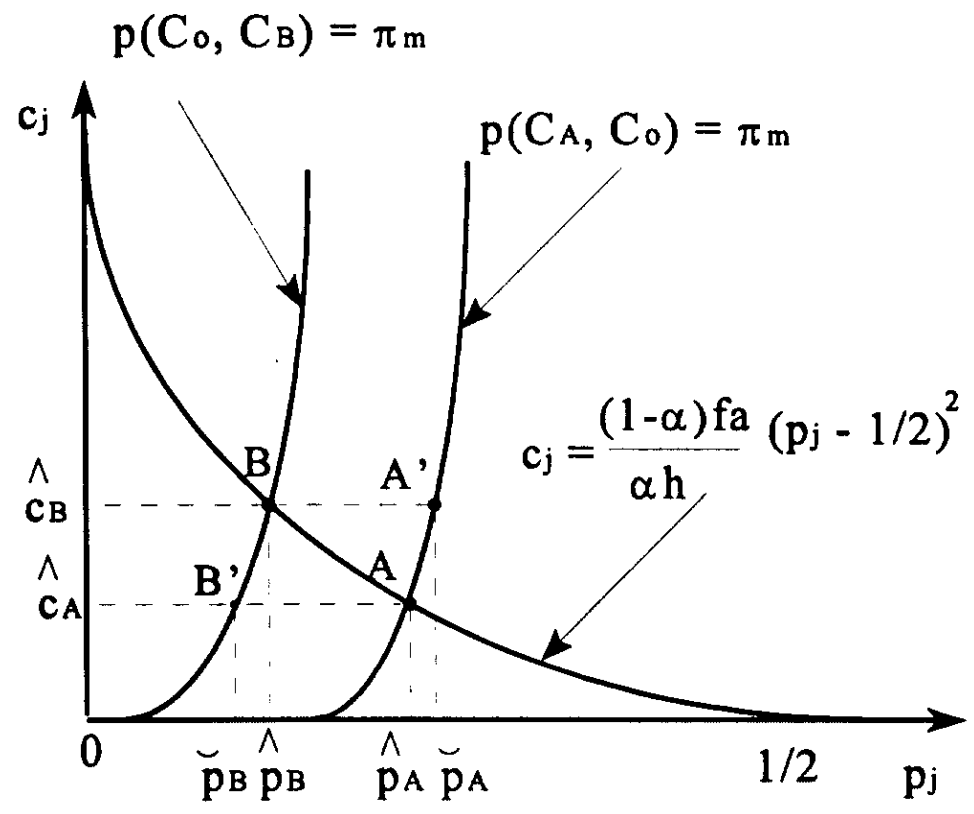

Figure 1

Note that for extreme values of $\pi_{m}$, i.e., when $\pi_{m}$ is close to 0 , it may be the case that the equivalent policies or even $\hat{p}_{A}$ and $\hat{p}_{B}$ are negative ${ }^{13}$. This is due to the fact that the final policy $p$ is a compromise between the platforms supported by both parties. To rule out this possibility, we restrict the values of $\pi_{m}$, so that the equivalent policy $\breve{p}_{B}$ be always feasible, i.e., $\breve{p}_{B} \in\left[0, \frac{1}{2}\right)$.

Assumption 1: We assume that $\pi_{m}$ is such that $\breve{p}_{B} \in\left[0, \frac{1}{2}\right)$.

As we shall show, by Assumption 1 and the assumption that we next introduce, it can be guaranteed that the platforms $\hat{p}_{A}, \hat{p}_{B}, \breve{p}_{A} \in[0,1]$ (see for instance Figure 1).

In Figure 2, we represent the interest group's indifference curves in $\left(c_{A}, p_{A}\right)$ space. These curves are denoted by $W_{0}, W_{1}$ and so on, where a higher index indicates a higher level of utility. The isovote curves for party $\mathrm{A}$ are $s_{1}, s_{2}$ and so on, a higher index indicates a higher percentage of votes.

\footnotetext{
${ }^{13}$ Since we are assuming that $\pi_{m}<\frac{1}{2}$, we do not mention the case of $\pi_{m}$ close to 1 .
} 
In the next assumption we are going to establish some conditions on the model:

First: note that as the platform of the parties $p_{A}\left(p_{B}\right)$ moves towards the objective of the interest group $\pi_{m}$, we have that the percentage of knowledgeable voters obtained by party $A$ (party $B$ ) decreases so that it may not be the case that the policy finally implemented moves towards $\pi_{m}$. In fact, by expression (2.3), we have that

$$
\frac{\partial p\left(C_{A}, C_{o}\right)}{\partial p_{A}}=\left(p_{A}-\frac{1}{2}\right) \frac{\partial s_{A}\left(C_{A}, C_{o}\right)}{\partial p_{A}}+s_{A}
$$

where $\frac{\partial s_{A}\left(C_{A}, C_{o}\right)}{\partial p_{A}}>0$ and so, the first term is negative and the second term is positive. For the purpose of this paper, we are going to assume that $\frac{\partial p\left(C_{A}, C_{o}\right)}{\partial p_{A}}>0$ $\left(\frac{\partial p\left(C_{o}, C_{B}\right)}{\partial p_{B}}>0\right)$. In particular, this assumption requires that the parameter $f$, be sufficiently small, so that the agents be not too sensible towards a modification of the parties' platforms.

Moreover, it follows that when $\frac{\partial p\left(C_{A}, C_{o}\right)}{\partial p_{A}}>0\left(\frac{\partial p\left(C_{o}, C_{B}\right)}{\partial p_{B}}>0\right)$ and the platform of the parties is such that $p\left(C_{A}, C_{o}\right)-\pi_{m}>0\left(p\left(C_{o}, C_{B}\right)-\pi_{m}>0\right)$, the derivative $\frac{\partial W\left(C_{A}, C_{o}\right)}{\partial p_{A}}=-a \frac{\partial p\left(C_{A}, C_{o}\right)}{\partial p_{A}}$ is negative $\left(\frac{\partial W\left(C_{o}, C_{B}\right)}{\partial p_{B}}=-a \frac{\partial p\left(C_{o}, C_{B}\right)}{\partial p_{B}}<0\right)$, hence, the interest group improves as the platforms of the parties move toward $\pi_{m}$.

Second: note that as the interest group contributes to the political campaign of the parties, it produces a double effect on the interest group' utility, that is described by:

$$
\frac{\partial W\left(C_{A}, C_{o}\right)}{\partial c_{A}}=-a \frac{\partial p\left(C_{A}, C_{o}\right)}{\partial c_{A}}-1
$$

where for $p_{A} \in\left[0, \frac{1}{2}\right)$, we have that $\frac{\partial p\left(C_{A}, C_{o}\right)}{\partial c_{A}}=\left(p_{A}-\frac{1}{2}\right) \frac{\partial s_{A}\left(C_{A}, C_{o}\right)}{\partial c_{A}}<0$. By $(3.2)$, we have that on the one hand, the campaign contributions enhance the votes of the parties and so, the weight of the platform $p_{A}\left(p_{B}\right)$ in the implemented policy increases. On the other hand, spending money always produces a disutility to the interest group. We shall assume that the net effect is negative so that $\frac{\partial W\left(C_{A}, C_{o}\right)}{\partial c_{A}}<0\left(\frac{\partial W\left(C_{o}, C_{B}\right)}{\partial c_{B}}<0\right)$. G-H refer to this assumption as "influence motive", which tells us that with the contributions the interest group only tries to induce the parties to support the platforms $p_{A}$ and $p_{B}$, i.e. it does not aim at modifying the election results. In particular, this assumption requires that the effectiveness of the political campaigns be not too high, i.e., that the parameter $h$ should not excess certain upper bound.

Third: we are going to assume that for those contract proposals where the lobby has not reached its political objective, the marginal substitution rate between campaign contributions and policy be always greater for the interest group 
than for the political parties. Analytically, it requires that the slopes of the interest group's indifference curves be steeper than the slope of the isovote curves

$$
\begin{aligned}
& -\frac{\frac{\partial W\left(C_{A}, C_{o}\right)}{\partial p_{A}}}{\frac{\partial W\left(C_{A}, C_{o}\right)}{\partial c_{A}}}>-\frac{\frac{\partial s_{A}\left(C_{A}, C_{o}\right)}{\partial p_{A}}}{\frac{\partial s_{A}\left(C_{A}, C_{o}\right)}{\partial c_{A}}} \\
& -\frac{\frac{\partial W\left(C_{o}, C_{B}\right)}{\partial p_{B}}}{\frac{\partial W\left(C_{o}, C_{B}\right)}{\partial c_{B}}}>-\frac{\frac{\partial s_{B}\left(C_{o}, C_{B}\right)}{\partial p_{B}}}{\frac{\partial s_{B}\left(C_{o}, C_{B}\right)}{\partial c_{B}}}
\end{aligned}
$$

In particular, when the parameter $a$ (that measures the disutility of the interest group when the final policy differs from $\pi_{m}$ ) is sufficiently high, the above inequalities are satisfied. When (3.3) and (3.4) hold, we have that for every marginal movement of the parties' platform toward the political objective of the interest group, the interest group is always ready to give more financial support than the minimum requested by the political parties for modifying their policy.

The next assumption contains the three conditions mentioned above:

Assumption 2: For all $C_{A} \in \mathcal{C}\left(C_{B} \in \mathcal{C}\right)$ such that $p\left(C_{A}, C_{o}\right)>\pi_{m}$ $\left(p\left(C_{o}, C_{B}\right)>\pi_{m}\right)$, we consider:

(I) $\frac{\partial p\left(C_{A}, C_{o}\right)}{\partial p_{A}}>0\left(\frac{\partial p\left(C_{o}, C_{B}\right)}{\partial p_{B}}>0\right)$

(II) $\frac{\partial W\left(C_{A}, C_{o}\right)}{\partial c_{A}}<0\left(\frac{\partial W\left(C_{o}, C_{B}\right)}{\partial c_{B}}>0\right)$

(III) $-\frac{\frac{\partial W\left(C_{A}, C_{O}\right)}{\partial p_{A}}}{\frac{\partial W\left(C_{A}, C_{O}\right)}{\partial c_{A}}}>-\frac{\frac{\partial s_{A}\left(C_{A}, C_{O}\right)}{\partial p_{A}}}{\frac{\partial s_{A}\left(C_{A}, C_{O}\right)}{\partial c_{A}}}\left(-\frac{\frac{\partial W\left(C_{O}, C_{B}\right)}{\partial p_{B}}}{\frac{\partial W\left(C_{O}, C_{B}\right)}{\partial c_{B}}}>-\frac{\frac{\partial s_{B}\left(C_{O}, C_{B}\right)}{\partial p_{B}}}{\frac{\partial s_{B}\left(C_{O}, C_{B}\right)}{\partial c_{B}}}\right)$.

An example satisfying Assumption 2 is shown in Figure 2.

As we show in Appendix 6.2, if the parameters of the model are such that

$$
\text { i) } h<\frac{2}{a \alpha} \text {, ii) } f<\frac{4 \alpha h\left(\frac{1}{2}-b\right)}{(1-\alpha)(a \alpha h+4)} \text {, }
$$

then Assumption 2 holds. In Appendix 6.2, we also show that from Assumption 2 if follows that the slope of the indifference curves evaluated at those $C_{A}, C_{B} \in \mathcal{C}$ such that $p\left(C_{A}, C_{o}\right)<\pi_{m}$, (respect to $\left.p\left(C_{o}, C_{B}\right)<\pi_{m}\right)$, are strictly positive.

An important implication of Assumptions 1 and 2 is next shown. 


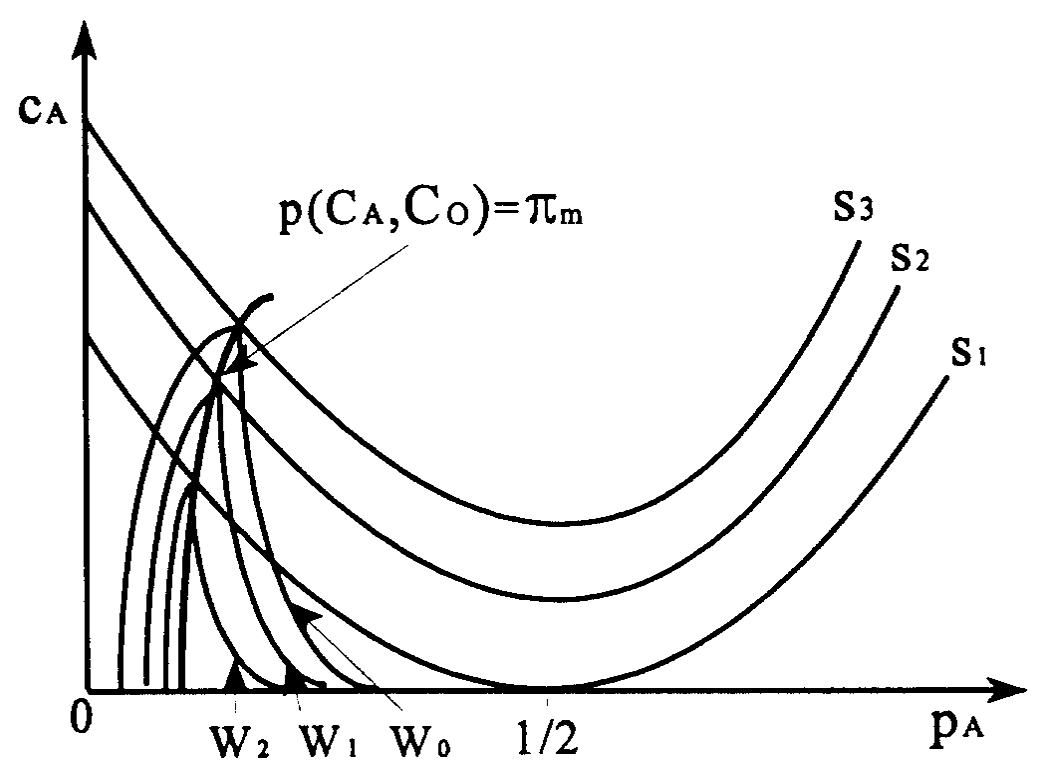

Figure 2

Lemma 3.8. Let $\hat{C}_{A}$ be the just-compensating contract for party $A$. Let $\bar{W}$ be a utility level satisfying that $\bar{W} \leqslant W\left(\hat{C}_{A}, C_{o}\right)$. Let $C_{A}^{\prime}=\left(c_{A}^{\prime}, p_{A}^{\prime}\right)$ be such that

$$
\begin{aligned}
C_{A}^{\prime} \in \underset{C_{A}}{\arg \max } & s_{A}\left(C_{A}, C_{o}\right) \\
& \text { s.t. } W\left(C_{A}, C_{o}\right) \geqslant \bar{W} .
\end{aligned}
$$

Then, under Assumptions 1 and $2, C_{A}^{\prime}$ is unique, feasible and $p\left(C_{A}^{\prime}, C_{o}\right)=\pi_{m}$.

Proof. (The proof can be followed in Figure 3).

Since $s_{A}\left(C_{A}, C_{o}\right)$ is strictly increasing in $c_{A}$ and $p_{A}$, the solution to the above maximization problem is achieved in the boundary of the restriction set, i.e. $C_{A}^{\prime}$ satisfies that $W\left(C_{A}^{\prime}, C_{o}\right)=\bar{W}$.

By Assumption 2, we have that for all $C_{A} \in \mathcal{C}$ such that $p\left(C_{A}, C_{o}\right)>\pi_{m}$, the slope of the indifference curve $W\left(C_{A}, C_{o}\right)$ is strictly negative and steeper than the slope of every isovote curve at that point and for all $C_{A} \in \mathcal{C}$ such that $p\left(C_{A}, C_{o}\right)<\pi_{m}$, the slope of the indifferent curves $W\left(C_{A}, C_{o}\right)$ is strictly positive. We obtain then, that the solution to the above problem is achieved in a unique point $C_{A}^{\prime}$ satisfying that $p\left(C_{A}^{\prime}, C_{o}\right)=\pi_{m}$. (See Figure 3$)$ 
Let us next show that $C_{A}^{\prime}$ is feasible.

Since $W\left(C_{A}^{\prime}, C_{o}\right)=\bar{W}$ and $p\left(C_{A}^{\prime}, C_{o}\right)=\pi_{m}$, we have that by hypothesis, $\bar{W} \leqslant W\left(\hat{C}_{A}, C_{o}\right)$, it follows that $c_{A}^{\prime} \geqslant \hat{c}_{A}$. Moreover, by Assumption $1, \breve{p}_{B} \geqslant 0$, and since $\hat{p}_{A} \geqslant \breve{p}_{B}$, it implies that $\hat{p}_{A} \geqslant 0$. And by Assumption 2 we have deduced that the slope of the implicit function $p\left(C_{A}, C_{o}\right)=\pi_{m}$ is strictly positive, so that if $c_{A}^{\prime} \geqslant \hat{c}_{A}, p_{A}^{\prime} \geqslant \hat{p}_{A}$ and then $p_{A}^{\prime} \geqslant 0$. Q.E.D.

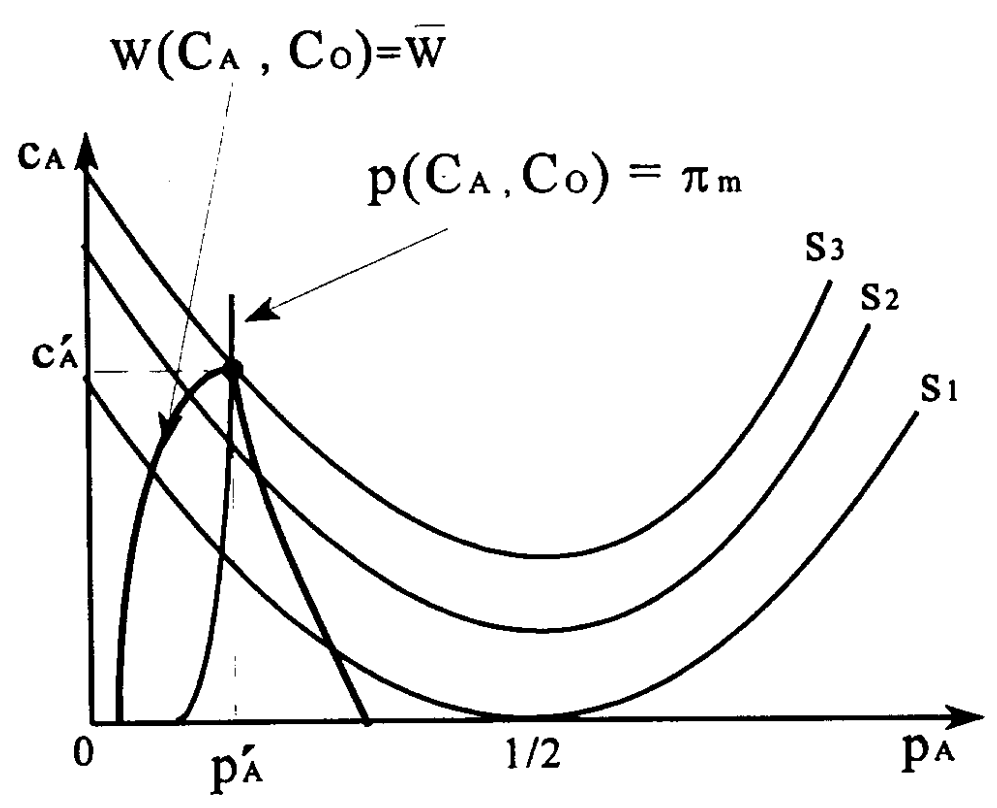

Figure 3

Remark 1. Showing the above lemma for party ${ }^{14} B$ is a symmetric case.

By Lemma 3.8 and Remark 1, we have that when the other party is not financed and Assumptions 1 and 2 hold, the contract proposals that maximize the votes of the parties, subject to providing certain level of utility to the interest group, are such that they achieve the political objective of the interest group.

\footnotetext{
${ }^{14}$ Let $\bar{W}$ be a utility level satisfying that $\bar{W} \leqslant W\left(C_{o}, \hat{C}_{B}\right)$. Let $C_{B}^{\prime}=\left(c_{B}^{\prime}, p_{B}^{\prime}\right)$ be such that $C_{B}^{\prime} \in \underset{C_{B}}{\arg \max } s_{B}\left(C_{o}, C_{B}\right)$ s.t. $W\left(C_{o}, C_{B}\right) \geqslant \bar{W}$. Then, under Assumptions 1 and $2, C_{B}^{\prime}$ is unique, feasible and $p\left(C_{o}, C_{B}^{\prime}\right)=\pi_{m}$.
} 


\section{Existence and Uniqueness of the Political Equilibrium}

We next describe a system of equations and we show that it has unique solution, furthermore, we prove that this solution is a political equilibrium.

Let $S$ be the system of simultaneous equations described by (1), (2) and (3):

$$
\begin{aligned}
W\left(C_{A}, C_{o}\right) & =W\left(C_{o}, C_{B}\right) \\
s_{A}\left(C_{A}, C_{o}\right) & =s_{A}\left(C_{o}, C_{B}\right) \\
p\left(C_{A}, C_{o}\right) & =p\left(C_{o}, C_{B}\right)=\pi_{m}
\end{aligned}
$$

Equation (1) requires that the interest group obtains equal utility accepting either of the contract proposals $C_{A}$ or $C_{B}$ and rejecting the other. By (2), it is required that the percentage of votes obtained by party $A$ when either of the contract proposals is accepted and the other rejected, be the same. And finally, equation (3) indicates that each of the contract proposals achieves policy $\pi_{m}$.

The system $S$ contains four equations with four unknowns. Note, that by $(1)$ and (3) we have that $W\left(C_{A}, C_{o}\right)=-c_{A}=W\left(C_{o}, C_{B}\right)=-c_{B}$, and so, in the solution $c_{A}=c_{B}$. We denote the amount of campaign contribution obtained in the solution as $c^{*}$.

Proposition 4.1. Under Assumptions 1 and 2, the system $S$ has unique solution $\left(C_{A}^{*}, C_{B}^{*}\right)=\left(\left(c^{*}, p_{A}^{*}\right)\left(c^{*}, p_{B}^{*}\right)\right)$. Moreover, $C_{A}^{*}$ and $C_{B}^{*}$ are feasible and satisfy that $c^{*} \in\left(\hat{c}_{A}, \hat{c}_{B}\right)$ and $s_{A}\left(C_{A}^{*}, C_{o}\right)>\frac{1}{2}+b$.

Proof. Let $\hat{C}_{B}=\left(\hat{c}_{B}, \hat{p}_{B}\right)$ be the just-compensating contract proposal for party $\mathrm{B}$ and $\breve{p}_{A}$ the equivalent policy for party $A$. Then, by definition, the contract proposals $\left(\hat{c}_{B}, \breve{p}_{A}\right)$ and $\hat{C}_{B}$, satisfy conditions (1) and (3) of system $S$ (see figure 1 ). Comparing the percentage of votes obtained by party $B$

$$
s_{B}\left(\left(\hat{c}_{B}, \breve{p}_{A}\right), C_{o}\right)<s_{B}\left(C_{o}, \hat{C}_{B}\right)
$$

Let $\hat{C}_{A}=\left(\hat{c}_{A}, \hat{p}_{A}\right)$ be the just-compensating contract proposal for party $\mathrm{A}$ and $\breve{p}_{B}$ the equivalent policy for party B. Then, by definition the contract proposals $\left(\hat{c}_{A}, \breve{p}_{B}\right)$ and $\hat{C}_{A}$ satisfy conditions (1) and (3) of system $S$ and

$$
s_{B}\left(\hat{C}_{A}, C_{o}\right)>s_{B}\left(C_{o},\left(\hat{c}_{A}, \breve{p}_{B}\right)\right) .
$$


$>$ From $p\left(C_{A}, C_{o}\right)=\pi_{m}$ and $p\left(C_{o}, C_{B}\right)=\pi_{m}, c_{A}$ can be obtained as a continuous function of $p_{A}$, and $c_{B}$ as a continuous function of $p_{B}$ respectively ${ }^{15}$. Moreover, since the derivatives of these functions $\frac{d c_{A}\left(p_{A}\right)}{d p_{A}}, \frac{d c_{B}\left(p_{B}\right)}{d p_{B}}$ are different from zero and continuous in $p_{A}$ and $p_{B}$, there is an inverse continuous function that we denote by $g_{A}$ and $g_{B}$, where each $g_{j}: \mathbb{R}_{+} \longrightarrow\left[0, \frac{1}{2}\right)$ and

$$
g_{A}\left(c_{A}\right)=p_{A}, g_{B}\left(c_{B}\right)=p_{B}
$$

that satisfies $\frac{d g_{j}\left(c_{j}\right)}{d c_{j}}>0$ for $j \in\{A, B\}$. Then, by (4.3) the percentages of votes obtained by party $\mathrm{B}$ in the contract proposals such that $p\left(C_{A}, C_{o}\right)=\pi_{m}$ and $p\left(C_{o}, C_{B}\right)=\pi_{m}$ are given respectively by

$$
s_{B}\left(C_{A}, C_{o}\right)=s_{B}\left(\left(c_{A}, g_{A}\left(c_{A}\right)\right), C_{o}\right), s_{B}\left(C_{o}, C_{B}\right)=s_{B}\left(C_{o},\left(c_{B}, g_{B}\left(c_{B}\right)\right)\right)
$$

which, by continuity of (4.3), are continuous functions in $c_{A}$ and $c_{B}$ respectively.

Let us define the function $\phi$ where

$$
\phi(c)=s_{B}\left(\left(c, g_{A}(c)\right), C_{o}\right)-s_{B}\left(C_{o},\left(c, g_{B}(c)\right)\right)
$$

which, by continuity of (4.4), is continuous. Since by (4.1), we know that $\phi\left(\hat{c}_{B}\right)<$ 0 and by (4.2), we know that $\phi\left(\hat{c}_{A}\right)>0$, by the intermediate value theorem there exists $c \in\left(\hat{c}_{A}, \hat{c}_{B}\right)$ such that $\phi(c)=0$. Let $c^{*} \equiv c$ and $p_{A}^{*}=g_{A}\left(c^{*}\right)$, $p_{B}^{*}=g_{B}\left(c^{*}\right) \cdot \phi\left(c^{*}\right)=0$, implies that $\left(c^{*}, p_{A}^{*}\right)$ and $\left(c^{*}, p_{B}^{*}\right)$ verify equation $(2)$ of $S$ and since $W\left(\left(c^{*}, p_{A}^{*}\right), C_{o}\right)=-c^{*}=W\left(C_{o},\left(c^{*}, p_{B}^{*}\right)\right),\left(c^{*}, p_{A}^{*}\right)$ and $\left(c^{*}, p_{B}^{*}\right)$ also verify equation (1) of $S$, so that this pair of contract proposals is a solution to $S$.

Since by Assumption 2 the slope of the implicit functions $p\left(C_{A}, C_{o}\right)=\pi_{m}$ and $p\left(C_{o}, C_{B}\right)=\pi_{m}$ are strictly positive, then $\frac{d g_{j}(c)}{d c}>0$ for $j \in\{A, B\}$, and so $s_{B}\left(\left(c, g_{A}(c)\right), C_{o}\right)$ is strictly decreasing ${ }^{16}$ in $c$ and $s_{B}\left(C_{o},\left(c, g_{B}(c)\right)\right)$ is strictly increasing ${ }^{17}$ in $c$. It implies that the slope of $\phi$ is strictly decreasing and then, for every $c^{\prime} \in \mathbb{R}_{+}$such that $c^{\prime}>c^{*}, \phi\left(c^{\prime}\right)>0$ and for every $c^{\prime}<c^{*}, \phi\left(c^{\prime}\right)<0$ and so, the solution to $S$ is unique.

\footnotetext{
${ }^{15}$ These functions are:
}

$$
c_{j}=\frac{\left(\pi_{m}-\frac{1}{2}\right)}{\left(p_{j}-\frac{1}{2}\right) \alpha h}-\frac{\left(K_{j}-(1-\alpha) f a\left(p_{j}-\frac{1}{2}\right)^{2}\right)}{\alpha h}
$$

where $K_{j}=\frac{1}{2}+b$ if $j=A$ and $K_{j}=\frac{1}{2}-b$ if $j=B$.

$16 \frac{d s_{B}\left(\left(c, g_{A}(c)\right), C_{0}\right)}{d c}=(1-\alpha) f a 2\left(g_{A}(c)-\frac{1}{2}\right) \frac{d g_{A}(c)}{d c}-\alpha h$ and $\frac{d g_{A}(c)}{d c}>0$, so that, the derivative is strictly negative.

$17 \frac{d s_{B}\left(C_{o},\left(c, g_{B}(c)\right)\right)}{d c}=-(1-\alpha) f a 2\left(g_{B}(c)-\frac{1}{2}\right) \frac{d g_{B}(c)}{d c}+\alpha h$ and $\frac{d g_{B}(c)}{d c}>0$, so that this derivative is strictly positive. 
Moreover, since $c^{*}<\hat{c}_{B}$ and $s_{B}\left(C_{o}, \hat{C}_{B}\right)=\frac{1}{2}-b$, we have that $s_{B}\left(C_{o},\left(c^{*}, p_{B}^{*}\right)\right)<$ $\frac{1}{2}-b$, it follow that $s_{A}\left(C_{o},\left(c^{*}, p_{B}^{*}\right)\right)>\frac{1}{2}+b$.

Finally, since $c^{*}>\hat{c}_{A}$ and $\frac{d g_{B}(c)}{d c}>0$, we have that $g_{B}\left(c^{*}\right)=p_{B}^{*}>\breve{p}_{B}=$ $g_{B}\left(\hat{c}_{A}\right)$. Then, since by Assumption $1, \breve{p}_{B}>0$, we have that $p_{B}^{*}>0$ and so, $\left(c^{*}, p_{B}^{*}\right)$ is feasible. Following a similar argument $g_{A}\left(c^{*}\right)=p_{A}^{*}>\hat{p}_{A}=g_{A}\left(\hat{c}_{A}\right)$ and so, $\left(c^{*}, p_{A}^{*}\right)$ is also feasible. Q.E.D.

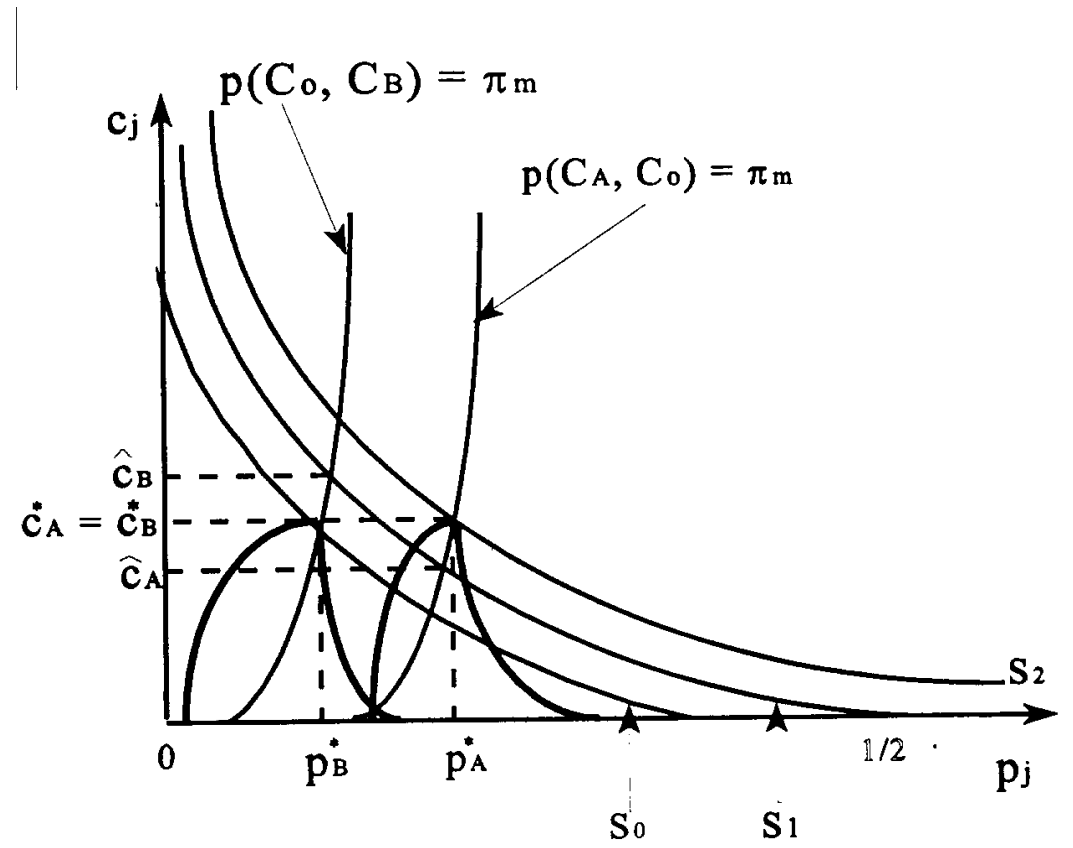

Figure 4

In Figure 4 we illustrate the contract proposals $C_{A}^{*}$ and $C_{B}^{*}$. In this graph it is shown how the pair of contract proposals $\left(C_{A}^{*}, C_{B}^{*}\right)$ satisfies the equations of system $S$. Moreover, note that for party $A, s_{A}\left(C_{A}^{*}, C_{o}\right)>\frac{1}{2}+b$ and for party B, $s_{B}\left(C_{o}, C_{B}^{*}\right)<\frac{1}{2}-b$.

Let us next show that $\left(C_{A}^{*}, C_{B}^{*}\right)$ is a political equilibrium.

Theorem 4.2. Under Assumptions 1 and 2, the pair of contract proposals $\left(C_{A}^{*}, C_{B}^{*}\right)$ is a political equilibrium.

Proof. Suppose not. It implies that at least one of the contract proposals is not a best response to the other party contract proposal. 
Let us first suppose that $C_{A}^{*}$ is not a best response to $C_{B}^{*}$. Then, there exists $C_{A}^{\prime}=\left(\overline{c_{A}^{\prime}, p_{A}^{\prime}}\right)$ such that $s_{A}\left(R\left(C_{A}^{\prime}, C_{B}^{*}\right)\right)>s_{A}\left(C_{A}^{*}, C_{o}\right) \equiv s^{*}$. Three cases must be considered
i) $\left(C_{A}^{\prime}, C_{B}^{*}\right) \in R\left(C_{A}^{\prime}, C_{B}^{*}\right)$
ii) $\left(C_{A}^{\prime}, C_{o}\right) \in R\left(C_{A}^{\prime}, C_{B}^{*}\right)$
iii) $\left(C_{o}, C_{o}\right) \in R\left(C_{A}^{\prime}, C_{B}^{*}\right)$

Suppose that $C_{A}^{\prime}$ verifies $\left.\mathbf{i}\right)$.

If $\left(c_{A}^{\prime}, p_{A}^{\prime}\right)$ is such that $c_{A}^{\prime}=0$, then, $s_{A}\left(C_{A}^{\prime}, C_{B}^{*}\right) \leqslant s^{*}$ which is a contradiction. If $c_{A}^{\prime}>0$, then,

$$
W\left(C_{A}^{\prime}, C_{B}^{*}\right)=-a\left|p\left(C_{A}^{\prime}, C_{B}^{*}\right)-\pi_{m}\right|-c_{A}^{\prime}-c^{*}<W\left(C_{o}, C_{B}^{*}\right)=-c^{*}
$$

and so $\left(C_{A}^{\prime}, C_{B}^{*}\right) \notin R\left(C_{A}^{\prime}, C_{B}^{*}\right)$ which is a contradiction.

Suppose now, that $C_{A}^{\prime}$ verifies ii).

Take $C_{A}^{\prime}$ as follows,

$$
\begin{aligned}
C_{A}^{\prime} \in & \underset{C_{A} \in \mathcal{C}}{\arg \max } s_{A}\left(C_{A}, C_{o}\right) \\
& \text { s.t. } W\left(C_{A}, C_{o}\right) \geqslant-c^{*}
\end{aligned}
$$

By Lemma 3.8, the solution to the above problem is unique and satisfies that $p\left(C_{A}^{\prime}, C_{o}\right)=\pi_{m}$ and $W\left(C_{A}^{\prime}, C_{o}\right)=-c^{*}$. It implies that $-c_{A}^{\prime}=-c^{*}$ and since $p\left(C_{A}^{\prime}, C_{o}\right)=\pi_{m}=p\left(C_{A}^{*}, C_{o}\right)$, we deduce that $p_{A}^{\prime}=p_{A}^{*}$. Then, $s_{A}\left(C_{A}^{\prime}, C_{o}\right)=s^{*}$. Since among all the contract proposals satisfying that $W\left(C_{A}, C_{o}\right) \geqslant W\left(C_{A}^{*}, C_{o}\right)$, $C_{A}^{\prime}$ is the one maximizing $s_{A}$, we reach a contradiction.

Suppose then, that $C_{A}^{\prime}$ verifies iii).

Since $s_{A}\left(C_{o}, C_{o}\right)=\frac{1}{2}+b$ and by Proposition $4.1, s^{*}>\frac{1}{2}+b$, which is a contradiction.

We conclude that $C_{A}^{*}$ is a best response to $C_{B}^{*}$.

Let us second suppose that $C_{B}^{*}$ is not a best response to $C_{A}^{*}$. Then, there exists $C_{B}^{\prime}=\overline{\left(c_{B}^{\prime}, p_{B}^{\prime}\right)}$ such that $s_{B}\left(R\left(C_{A}^{*}, C_{B}^{\prime}\right)\right)>1-s^{*}$. Three cases must be considered
a) $\left(C_{A}^{*}, C_{B}^{\prime}\right) \in R\left(C_{A}^{*}, C_{B}^{\prime}\right)$
b) $\left(C_{o}, C_{B}^{\prime}\right) \in R\left(C_{A}^{*}, C_{B}^{\prime}\right)$
c) $\left(C_{o}, C_{o}\right) \in R\left(C_{A}^{*}, C_{B}^{\prime}\right)$

For the cases $\mathbf{a}$ ) and $\mathbf{b}$ ), the same arguments as the ones applied above for party A (now in terms of party B), lead to a contradiction.

Suppose then, that $C_{B}^{\prime}$ verifies $\mathbf{c}$ ). 
Now consider the following maximization problem

$$
\begin{aligned}
& \max _{C_{B} \in \mathcal{C}} s_{B}\left(C_{o}, C_{B}\right) \\
& \text { s.t. } W\left(C_{o}, C_{B}\right) \geqslant-c^{*}
\end{aligned}
$$

By Lemma 3.8 and Remark 1, the unique solution to the above problem satisfies that $p\left(C_{o}, C_{B}\right)=\pi_{m}$ and $W\left(C_{o}, C_{B}\right)=-c^{*}$, then by the same argument used for party $\mathrm{A}$ we deduce that the solution is $\left(c^{*}, p_{B}^{*}\right)$. Since $s_{B}\left(C_{o}, C_{B}^{*}\right)=1-s^{*}$ and by Proposition 4.1 we have that $1-s^{*}<\frac{1}{2}-b$, which is equivalent to $1-s^{*}<s_{B}\left(C_{o}, C_{o}\right)$. Then, $C_{o}$ is not a solution to the above maximization problem since $W\left(C_{o}, C_{o}\right)<-c^{*}$ and so $\left(C_{o}, C_{o}\right) \notin R\left(C_{A}^{*}, C_{B}^{\prime}\right)$, a contradiction. Q.E.D.

By Theorem 4.2, we have shown that the unique solution to the system of equations $S$, is a political equilibrium. In this equilibrium, the lobby finances only one party and is indifferent between financing one or the other political party. Moreover, it is always the case that the lobby achieves its political objective $\pi_{m}$.

$>$ From the parties point of view, the same election result is obtained when one or the other party is financed. However, in both cases the more popular party (party A) benefits in terms of votes with regard to the case where there is no interest group.

We next show that the described political equilibrium is unique. We firstly prove that there are certain pairs of contract proposals $\left(C_{A}, C_{B}\right)$, that can be discarded from qualifying as a political equilibrium.

In the following lemma, we show that there can not be a political equilibrium where none of the contract proposals are accepted.

Lemma 4.3. Under Assumptions 1 and 2, if $\left(C_{A}, C_{B}\right)$ is a political equilibrium $\left(C_{o}, C_{o}\right) \notin R\left(C_{A}, C_{B}\right)$.

Proof. (It is in the appendix).

As a second step, we show that there can not be a political equilibrium where the interest group accepts at the same time the contract proposals of both parties.

Lemma 4.4. Let $C_{A} \neq C_{o}$ and $C_{B} \neq C_{o}$. Then, under Assumptions 1 and 2 , if $\left(C_{A}, C_{B}\right)$ is a political equilibrium $\left(C_{A}, C_{B}\right) \notin R\left(C_{A}, C_{B}\right)$.

Proof. (It is in the appendix). 
As a third step, we show that those contract proposals that do not achieve policy $\pi_{m}$, can not qualify as a best response.

Lemma 4.5. Let $C_{A}\left(C_{B}\right)$ such that $p\left(C_{A}, C_{o}\right) \neq \pi_{m}\left(p\left(C_{o}, C_{B}\right) \neq \pi_{m}\right)$. Then, under Assumption 1 and 2 , if $\left(C_{A}, C_{B}\right)$ is a political equilibrium $\left(C_{A}, C_{o}\right) \notin$ $R\left(C_{A}, C_{B}\right)\left(\left(C_{o}, C_{B}\right) \notin R\left(C_{A}, C_{B}\right)\right)$.

Proof. (It is in the appendix).

And finally we show uniqueness of equilibrium.

Theorem 4.6. Under Assumption 1 and 2, the political equilibrium $\left(C_{A}^{*}, C_{B}^{*}\right)$ is unique.

Proof. (It is in the appendix).

\section{Conclusions}

In this section, we firstly analyze the obtained equilibrium and secondly, it is compared with the equilibrium obtained by G-H in their approach.

We next establish some links between market competition in Bertrand's model and parties competition in our model.

Under our proposal of negotiation, the political parties are competing in a two dimensional space, i.e., they compete simultaneously in policies and amount of campaign contribution. Therefore, it is not possible to deduce an standard reaction function (as in Bertrand competition) for each of the parties which may facilitate the equilibrium analysis. We show however, that our equilibrium has some features in common with Bertrand's equilibrium. We next state some of these similarities:

1- Each of the parties offers a policy which at the end implements the objective of the interest group $\pi_{m}$. In market terms we could say that the parties supply "an homogenous good".

As it follows from Lemma 3.8, from the parties point of view, the best proposal that they can make to the interest group consist of offering a policy which at the end implements $\pi_{m}$. Furthermore, from the interest group point of view, it is as good to obtain policy $\pi_{m}$ from one or the other political party.

2- Parties just compete in amounts of campaign contribution. In markets terms we could say that parties "compete in prices".

Each of the parties knows that the interest group, once it obtains $\pi_{m}$, shall benefit from contributing with the minimal amount of campaign funds. However, 
as the contribution decreases the parties lose impressionable voters which entirely depend on it.

3-In equilibrium the proposals of the parties converge, i.e., $c_{A}=c_{B}=c^{*}$. In market terms we could say that parties "set equal prices".

Clearly, by Theorem 4.2, none of the parties can announce an amount of campaign contribution lower than $c^{*}$. The reason is, that the cost (in terms of votes) of reducing the amount of contribution exceeds the benefits (in terms of votes) from being financed by the interest group. Hence, in the case that both parties be equal, none of the parties can benefit from being financed by the interest group. In our equilibrium, however, party A benefits, independently of which party is actually financed, since it has an initial advantage in votes respect to party B.

Let us next compare our result with G-H' result.

G-H suppose that the negotiation process is initiated by the interest group. We suggest alternatively, that the negotiation is initiated by the political parties. G-H find that the interest group always gives funds to both political parties. We find however, that the interest group only gives funds to one of the parties. Furthermore, with our approach, the election results always shift in favor of the most popular party, whereas G-H obtain that, in general, the results of the elections are not affected. Therefore, the most popular party is mostly interested in our negotiation process since it improves its election results.

However, from the interest group point of view, it is more profitable to be the one who initiates the negotiations since it achieves the same political objective with both approaches but negotiations are cheaper under G-H's approach.

It is important to point out, that assuming that the implemented policy is determined by policy compromise, does not imply that the interest group always finances both parties. As we have already shown, it is the process of negotiation which determines whether one or both parties are financed.

If we assume that the legislature operates by majority voting, it is not difficult to show ${ }^{18}$ that our proposal of negotiation gives similar results. In this case, the most popular party (party A) is the only party that is financed ${ }^{19}$ and it obtains better election results than under policy compromise. Furthermore, the interest

\footnotetext{
${ }^{18}$ For this result we only require a relaxed version of Assumption 1 and part (III) of Assumption 2.

${ }^{19}$ Grossman and Helpman (1996a) show in the Appendix that when the parties are symmetric their result is the same than the symmetric equilibrum that emerges when the legislature operates by strict majority rule and parties maximize their chances of winning a majority.
} 
group always obtains its political objective $\pi_{m}$.

$>$ From the comparison of our results and G-H's, we leave the following questions open: What can be deduced from the empirical data? Is there a correlation between the negotiation process and the two different results, i.e., financing one or both parties? Is there a correlation between the negotiation process and the election results?

Some additional arguments that can explain why some interest groups finance one or both political parties, are related to the degree of uncertainty about the election results. With this paper we have emphasized that the order of the campaign negotiations is also a crucial issue that explains why some interest groups finance one or both competing political parties. Furthermore we have provided a powerful argument which explains why the campaign funding influences the election results.

We lead for future research the extension of this model to the case in which there are several interest groups.

\section{Appendix}

\subsection{The preferences of the interest group}

G-H assume that the preferences of the interest group are represented by the joint surplus of the members of this group,

$$
W\left(p, c_{A}, c_{B}\right)=-\int_{\pi_{1}}^{\pi_{2}} a|p-\pi| d \pi-c_{A}-c_{B},
$$

They suggest that the optimal contract proposals that the interest group offers to the parties is obtained from the following maximization problem that we denoted by M:

$$
\begin{array}{ccc}
\underset{c_{A}, c_{B}, p_{A}, p_{B}}{\operatorname{Max}} & W\left(p, c_{A}, c_{B}\right) \\
\text { s.t. } & c_{A} \geqslant \frac{(1-\alpha) f a}{\alpha h}\left(p_{A}-\frac{1}{2}\right)^{2} \\
& c_{B} \geqslant \frac{(1-\alpha) f a}{\alpha h}\left(p_{B}-\frac{1}{2}\right)^{2} \\
& c_{A}, c_{B} \geqslant 0, p_{A}, p_{B} \in[0,1]
\end{array}
$$

The two first constraints indicate the minimal compensation that one party has to receive to support a pliable platform different from $p_{j}=\frac{1}{2}$ (see expression $(3.1)$ ). G-I firstly consider the case in which both constraints bind and they obtain 
that, in the solution, the interest group finances both parties, and gives more contribution to the more popular party. Note that G-H's results follows from the convexity of the functions

$$
c_{j}=\frac{(1-\alpha) f a}{\alpha h}\left(p_{j}-\frac{1}{2}\right)^{2}
$$

as we next show. The intuition is the following: let $\left(c_{A}, p_{A}\right)$ such that $p\left(c_{A}, p_{A}, 0, \frac{1}{2}\right)=$ $\pi_{m}$ and let $\left(c_{A}^{\prime}, p_{A}^{\prime}\right)$ and $\left(c_{B}, p_{B}\right)$ such that $p\left(c_{A}^{\prime}, p_{A}^{\prime}, c_{B}, p_{B}\right)=\pi_{m}$. Then, by $(6.2)$, it is always the case that $c_{A}>c_{A}^{\prime}+c_{B}$, and so, for the interest group, it is cheaper to obtain the policy $\pi_{m}$ financing both parties than financing only one.

In our approach, we have assumed that the preferences of the interest group are represented by

$$
W\left(p, c_{A}, c_{B}\right)=-a\left|p-\pi_{m}\right|-c_{A}-c_{B}
$$

where, $\pi_{m}$ can be interpreted as the most preferred pliable platform for the median agent of this group. And substituting (6.1) by (6.3) in problem M' objective function, we find that, in the solution, the interest group also finances both parties (it also follows from the convexity of (6.2)).

Finally, note that one of the differences between the utility functions (6.1) and (6.3) is that $(6.1)$ is everywhere differentiable and (6.3) is not differentiable when $p\left(c_{A}, p_{A}, c_{B}, p_{B}\right)=\pi_{m}$. As we show in Lemma 3.8 , this difference is crucial in order to obtain our results.

\subsection{Analysis of Assumption 2}

By condition (I) we require that ${ }^{20}$

$$
\frac{\partial p\left(C_{o}, C_{B}\right)}{\partial p_{B}}=\frac{1}{2}-b-3\left(p_{B}-\frac{1}{2}\right)^{2}(1-\alpha) f a+\alpha h c_{B}>0
$$

Note that if (6.4) is strictly positive when $c_{B}=0$ and $p_{B}=0$, it is also strictly positive for all $c_{B}>0$ and $p_{B} \in(0,1]$. Substituting the values of $c_{B}=0, p_{B}=0$ and rearranging terms, we deduce that $(6.4)$ is strictly positive if

$$
f<\frac{4\left(\frac{1}{2}-b\right)}{3(1-\alpha) a} \text {. }
$$

Regarding condition (II), we require that

\footnotetext{
${ }^{20}$ Note that if $\frac{\partial p\left(C_{o}, C_{B}\right)}{\partial p_{B}}>0$ for $\forall c_{B}, p_{B} \in \mathbb{R}_{+} \times[0,1]$, then $\frac{\partial p\left(C_{A}, C_{o}\right)}{\partial p_{A}}>0$ for $\forall c_{A}, p_{A} \in$ $\mathbb{R}_{+} \times[0,1]$.
} 


$$
\frac{\partial W\left(C_{A}, C_{o}\right)}{\partial c_{A}}=a\left(\frac{1}{2}-p_{A}\right) \alpha h-1<0, \quad \frac{\partial W\left(C_{o}, C_{B}\right)}{\partial c_{B}}=a\left(\frac{1}{2}-p_{B}\right) \alpha h-1<0
$$

Note that if these derivatives are strictly negative at $p_{A}=0$ and $p_{B}=0,(6.6)$ holds for all $p_{j} \in\left[0, \frac{1}{2}\right)$. Substituting the values of $p_{A}=0$ and $p_{B}=0$, we find that the following inequality guarantees that (6.6) holds:

$$
a \alpha h<2 .
$$

Finally, regarding (III), we calculate this inequality in term of party B:

$$
\frac{-a\left(s_{B}-2\left(p_{B}-\frac{1}{2}\right)^{2}(1-\alpha) f a\right)}{a\left(\frac{1}{2}-p_{B}\right) \alpha h-1}>\frac{2 f a(1-\alpha)\left(\frac{1}{2}-p_{B}\right)}{\alpha h} .
$$

Simplifying,

$$
f a(1-\alpha)\left(p_{B}-\frac{1}{2}\right)^{2}+\frac{2 f(1-\alpha)\left(\frac{1}{2}-p_{B}\right)}{\alpha h}<\frac{1}{2}-b+\alpha h c_{B} .
$$

Note that if this inequality holds when $c_{B}=0, p_{B}=0$ and $h=\frac{2}{a \alpha}$, it is satisfied in general. Substituting these values we obtain that

$$
f<\frac{4 \alpha h\left(\frac{1}{2}-b\right)}{(1-\alpha)(a \alpha h+4)}
$$

Finally, it is easy to demonstrate that (6.8) also guarantees that the inequality of (III) expressed in terms of party $\mathrm{A}$ also holds.

Let us finally show that conditions $(6.7)$ and (6.8) imply (6.5): let $\gamma=\frac{4\left(\frac{1}{2}-b\right)}{3(1-\alpha) a}$, then, (6.5) can be expressed as $f<\gamma$.

By (6.8) we have that $f<\gamma \frac{3 a \alpha h}{a \alpha h+4}$, moreover by (6.7) it is easy to deduce that $\frac{3 a \alpha h}{a \alpha h+4}<1$, and consequently, we have that $f<\gamma$.

\subsection{Proves of Section 4}

\section{Proof of Lemma 4.3:}

Suppose to the contrary that $\left(C_{A}, C_{B}\right)$ is a political equilibrium where $\left(C_{o}, C_{o}\right) \in$ $R\left(C_{A}, C_{B}\right)$. Since $R\left(C_{A}, C_{B}\right)$ may contain one or more alternatives, we consider two cases: 
Case 1: $s_{A}\left(R\left(C_{A}, C_{B}\right)\right) \leqslant \frac{1}{2}+b$.

Let us define the following contract proposal $C_{A}^{\prime}$,

$$
\begin{aligned}
C_{A}^{\prime} \in \underset{C_{A} \in \mathcal{C}}{\arg \max } s_{A}\left(C_{A}, C_{o}\right) \\
\text { s.t. } W\left(C_{A}, C_{o}\right) \geqslant W\left(C_{o}, C_{o}\right)+\varepsilon
\end{aligned}
$$

with $\varepsilon>0$ and close enough to 0 . From Lemma 3.8, $C_{A}^{\prime}$ is feasible and satisfies that $p\left(C_{A}^{\prime}, C_{o}\right)=\pi_{m}$. By Assumption 2, the slope of the indifferent curve $W$ evaluated at $C_{A}=C_{o}$ and $C_{B}=C_{o}$, is steeper than the slope of the isovote curve $s_{A}$ evaluated at the same point, $s_{A}\left(C_{A}^{\prime}, C_{o}\right)>\frac{1}{2}+b$. Since $R\left(C_{A}^{\prime}, C_{B}\right)=\left\{\left(C_{A}^{\prime}, C_{o}\right)\right\}$ and $s_{A}\left(R\left(C_{A}^{\prime}, C_{B}\right)\right)>s_{A}\left(R\left(C_{A}, C_{B}\right)\right)$ we obtain that $C_{A}$ is not a best response to $C_{B}$.

Case 2: when $s_{A}\left(R\left(C_{A}, C_{B}\right)\right)>\frac{1}{2}+b$.

It implies that $s_{B}\left(R\left(C_{A}, C_{B}\right)\right)<\frac{1}{2}+b$. Then, the same argument described in Case 1 , now in terms of party B, leads to a contradiction. Q.E.D.

\section{Proof of Lemma 4.4:}

Suppose to the contrary that $\left(C_{A}, C_{B}\right)$ is a political equilibrium where $\left(C_{A}, C_{B}\right) \in$ $R\left(C_{A}, C_{B}\right)$. We consider the following four cases:

Case 1: $s_{A}\left(R\left(C_{A}, C_{B}\right)\right) \leqslant \frac{1}{2}+b$ and $s_{B}\left(C_{o}, C_{B}\right)<\frac{1}{2}-b$.

Consider the contract proposal $C_{A}^{\prime}=C_{o}$. Since $\left(C_{o}, C_{B}\right)$ belongs to a lower isovote curve than $\left(C_{o}, C_{o}\right)$, from Assumption 2, we have that $W\left(C_{o}, C_{B}\right)>$ $W\left(C_{o}, C_{o}\right)$. Consequently, $R\left(C_{A}^{\prime}, C_{B}\right)=\left\{\left(C_{o}, C_{B}\right)\right\}$ and since $s_{A}\left(C_{o}, C_{B}\right) \leqslant \frac{1}{2}+b$, $s_{A}\left(R\left(C_{A}^{\prime}, C_{B}\right)\right)>s_{A}\left(R\left(C_{A}, C_{B}\right)\right)$ which is a contradiction.

Case 2: $s_{A}\left(R\left(C_{A}, C_{B}\right)\right) \leqslant \frac{1}{2}+b$ and $s_{B}\left(C_{o}, C_{B}\right) \geqslant \frac{1}{2}-b$.

Consider then, the contract proposal $C_{A}^{\prime}=\left(c_{A}^{\prime}, p_{A}^{\prime}\right)$ where $c_{A}^{\prime}=c_{B}-\varepsilon$ (with $\varepsilon>0$ and close enough to 0$)$ and $p_{A}^{\prime}$ satisfying that

$$
p\left(C_{A}^{\prime}, C_{o}\right)=p\left(C_{o}, C_{B}\right) .
$$

Assumption 2 requires that $\frac{\partial p\left(C_{A}, C_{o}\right)}{\partial p_{A}}>0$ and since for every contract proposal $C$ we have that party $A$ obtains more votes, i.e., $s_{A}\left(C, C_{o}\right)>s_{B}\left(C_{o}, C\right)$ then, by (2.3), we have that (6.9) only satisfies if $p_{A}^{\prime}>p_{B}$. Consequently, since $s_{B}\left(C_{o}, C_{B}\right) \geqslant$ $\frac{1}{2}-b$

$$
s_{A}\left(C_{A}^{\prime}, C_{o}\right)>\frac{1}{2}+b .
$$


And since $s_{A}\left(C_{A}^{\prime}, C_{B}\right)=\frac{1}{2}+b+(1-\alpha) f a\left[\left(p_{B}-\frac{1}{2}\right)^{2}-\left(p_{A}^{\prime}-\frac{1}{2}\right)^{2}\right]+\alpha h\left(c_{A}^{\prime}-c_{B}\right)$ where the term in square brackets is positive and $c_{A}^{\prime}-c_{B} \simeq 0$, we deduce that

$$
s_{A}\left(C_{A}^{\prime}, C_{B}\right)>\frac{1}{2}+b
$$

By (6.9) and since $c_{A}^{\prime}=c_{B}-\varepsilon$, we have that

$$
W\left(C_{A}^{\prime}, C_{o}\right)>W\left(C_{o}, C_{B}\right) .
$$

Suppose that $W\left(C_{o}, C_{o}\right) \leqslant \max \left\{W\left(C_{A}^{\prime}, C_{B}\right), W\left(C_{A}^{\prime}, C_{o}\right)\right\}$, in this case by $(6.10)$ trough $(6.12), s_{A}\left(R\left(C_{A}^{\prime}, C_{B}\right)\right)>\frac{1}{2}+b$, and thus, $C_{A}$ is not a best response which is a contradiction.

Suppose second that $W\left(C_{o}, C_{o}\right)>\max \left\{W\left(C_{A}^{\prime}, C_{B}\right), W\left(C_{A}^{\prime}, C_{o}\right)\right\}$, thus $(6.12)$ implies that $R\left(C_{A}^{\prime}, C_{B}\right)=\left\{\left(C_{o}, C_{o}\right)\right\}$. Then, consider the following contract proposal $C_{A}^{\prime \prime}$

$$
\begin{aligned}
C_{A}^{\prime \prime} \in & \underset{C_{A} \in \mathcal{C}}{\arg \max } s_{A}\left(C_{A}, C_{o}\right) \\
& \text { s.t. } W\left(C_{A}, C_{o}\right) \geqslant W\left(C_{o}, C_{o}\right)+\varepsilon
\end{aligned}
$$

(where $\varepsilon>0$ and close enough to 0 ). By Lemma 3.8, $C_{A}^{\prime \prime}$ is unique and feasible and by Assumption 2 we have that $s_{A}\left(C_{A}^{\prime \prime}, C_{o}\right)>s_{A}\left(C_{o}, C_{o}\right)$. Since $R\left(C_{A}^{\prime \prime}, C_{B}\right)=$ $\left\{\left(C_{A}^{\prime \prime}, C_{o}\right)\right\}$ and $s_{A}\left(R\left(C_{A}^{\prime \prime}, C_{B}\right)\right)>\frac{1}{2}+b, C_{A}$ is not a best response which is a contradiction.

Case 3: $s_{A}\left(R\left(C_{A}, C_{B}\right)\right)>\frac{1}{2}+b$ and $s_{A}\left(C_{A}, C_{o}\right) \leqslant \frac{1}{2}+b$.

We have then that, $s_{B}\left(R\left(C_{A}, C_{B}\right)\right)<\frac{1}{2}-b$. By the same argument than in the Case 1 , now in terms of party $B$, we reach a contradiction.

Case 4: $s_{A}\left(R\left(C_{A}, C_{B}\right)\right)>\frac{1}{2}+b$ and $s_{A}\left(C_{A}, C_{o}\right)>\frac{1}{2}+b$.

We distinguish two subcases:

Case 4.1: $s_{A}\left(R\left(C_{A}, C_{B}\right)\right)>s_{A}\left(C_{A}, C_{o}\right)$.

This implies that $s_{B}\left(R\left(C_{A}, C_{B}\right)\right)<s_{B}\left(C_{A}, C_{o}\right)<\frac{1}{2}-b$. And since for $C_{B}^{\prime}=C_{o}$, we have that $R\left(C_{A}, C_{B}^{\prime}\right)$ is either $\left(C_{A}, C_{o}\right)$ or $\left(C_{o}, C_{o}\right)$ or both, we obtain then that $s_{B}\left(R\left(C_{A}, C_{B}^{\prime}\right)\right)>s_{B}\left(R\left(C_{A}, C_{B}\right)\right)$. Consequently, $C_{B}$ is not a best response to $C_{A}$ which is a contradiction.

Case 4.2: $s_{A}\left(R\left(C_{A}, C_{B}\right)\right) \leqslant s_{A}\left(C_{A}, C_{o}\right)$ and $W\left(C_{A}, C_{B}\right)>W\left(C_{o}, C_{B}\right)$. Consider then, the contract proposal $C_{A}^{\prime}=\left(c_{A}^{\prime}, p_{A}^{\prime}\right)$ where $c_{A}^{\prime}=c_{A}$, and $p_{A}^{\prime}$ satisfies that

$$
W\left(C_{A}^{\prime}, C_{B}\right)=\max \left\{W\left(C_{o}, C_{B}\right), W\left(C_{o}, C_{o}\right)\right\}+\varepsilon
$$

(with $\varepsilon>0$ and close enough to 0 ). Since by Assumption 2 we have that $\frac{\partial W\left(C_{A}, C_{B}\right)}{\partial p_{A}}<0, p_{A}^{\prime}>p_{A}$ and since $W$ is continuous in $p_{A}, C_{A}^{\prime}$ is feasible. Thus, 
$R\left(C_{A}^{\prime}, C_{B}\right)$ is either $\left(C_{A}^{\prime}, C_{B}\right)$ or $\left(C_{A}^{\prime}, C_{o}\right)$ or both so that $s_{A}\left(R\left(C_{A}^{\prime}, C_{B}\right)\right)>$ $s_{A}\left(R\left(C_{A}, C_{B}\right)\right)$, which contradicts that $C_{A}$ is a best response to $C_{B}$.

Case 4.3: $s_{A}\left(R\left(C_{A}, C_{B}\right)\right) \leqslant s_{A}\left(C_{A}, C_{o}\right)$ and $W\left(C_{A}, C_{B}\right)=W\left(C_{o}, C_{B}\right)$. Consider then the contract proposal $C_{B}^{\prime}$

$$
\begin{array}{r}
C_{B}^{\prime} \in \underset{C_{B}}{\arg \max } s_{B}\left(C_{o}, C_{B}\right) \\
\text { s.t. } W\left(C_{o}, C_{B}\right) \geqslant \tilde{W}
\end{array}
$$

where $\tilde{W}=W\left(C_{o}, C_{B}\right)+\varepsilon$, with $\varepsilon>0$ and close enough to 0 . Since $s_{A}\left(R\left(C_{A}, C_{B}\right)\right) \leqslant$ $s_{A}\left(C_{A}, C_{o}\right)$ and $s_{A}\left(C_{A}, C_{o}\right)>\frac{1}{2}+b$, we have that $s_{B}\left(C_{o}, C_{B}\right) \geqslant \frac{1}{2}-b$. This implies that $C_{B}^{\prime}$ is feasible. And by Lemma 3.8, we know that $C_{B}^{\prime}$ satisfies that $p\left(C_{o}, C_{B}^{\prime}\right)=\pi_{m}$. Hence, $R\left(C_{A}, C_{B}^{\prime}\right)=\left\{\left(C_{o}, C_{B}^{\prime}\right)\right\}$ (note that $\left(C_{A}, C_{B}\right) \in$ $R\left(C_{A}, C_{B}\right)$ implies that $W\left(C_{A}, C_{o}\right) \leqslant W\left(C_{A}, C_{B}\right)$ and since we suppose that $W\left(C_{A}, C_{B}\right)=W\left(C_{o}, C_{B}\right)$, from the restriction of the maximization problem $\left.\left(C_{A}, C_{o}\right) \notin R\left(C_{A}, C_{B}^{\prime}\right)\right)$. Moreover, since $\left(C_{A}, C_{B}\right) \in R\left(C_{A}, C_{B}\right)$, we have that $p\left(C_{o}, C_{B}\right)>\pi_{m}$, and then, for $\varepsilon$ sufficiently small and by Assumption 2, we obtain that $s_{B}\left(C_{o}, C_{B}\right)<s_{B}\left(C_{o}, C_{B}^{\prime}\right)$. Thus, $s_{B}\left(R\left(C_{A}, C_{B}^{\prime}\right)\right)>\frac{1}{2}-b$, and so $s_{B}\left(R\left(C_{A}, C_{B}^{\prime}\right)\right)>s_{B}\left(R\left(C_{A}, C_{B}\right)\right)$, a contradiction. Q.E.D.

\section{Proof of Lemma 4.5:}

Suppose to the contrary that there is a political equilibrium $\left(C_{A}^{\prime}, C_{B}^{\prime}\right)$ and $\left(C_{A}^{\prime}, C_{o}\right) \in$ $R\left(C_{A}^{\prime}, C_{B}^{\prime}\right), p\left(C_{A}^{\prime}, C_{o}\right) \neq \pi_{m}$.

Let $\hat{C}_{A}$ the just-compensating contract for party A. According to the restriction of the maximization problem in Lemma 3.8, we distinguish two cases:

Case 1: $W\left(C_{A}^{\prime}, C_{o}\right) \leqslant W\left(\hat{C}_{A}, C_{o}\right)$.

Consider then, the contract proposal $C_{A}^{\prime \prime}$

$$
\begin{aligned}
C_{A}^{\prime \prime} \in & \underset{C_{A} \in \mathcal{C}}{\arg \max } s_{A}\left(C_{A}, C_{o}\right) \\
& \text { s.t. } W\left(C_{A}, C_{o}\right) \geqslant W\left(C_{A}^{\prime}, C_{o}\right)
\end{aligned}
$$

By Lemma 3.8, $C_{A}^{\prime \prime}$ is feasible and satisfies that $p\left(C_{A}^{\prime \prime}, C_{o}\right)=\pi_{m}$, this implies that $C_{A}^{\prime \prime} \neq C_{A}^{\prime}$ and so $s_{A}\left(C_{A}^{\prime}, C_{o}\right)>s_{A}\left(C_{A}^{\prime}, C_{o}\right)$. By the restriction of the problem (6.13), we know that $W\left(C_{A}^{\prime}, C_{o}\right)=W\left(C_{A}^{\prime \prime}, C_{o}\right)$, and since $\left(C_{A}^{\prime}, C_{o}\right) \in R\left(C_{A}^{\prime}, C_{B}^{\prime}\right)$, we have that $\left(C_{A}^{\prime \prime}, C_{o}\right) \in R\left(C_{A}^{\prime \prime}, C_{B}^{\prime}\right)$. Consequently and since $s_{A}\left(C_{A}^{\prime}, C_{o}\right)>$ $s_{A}\left(C_{A}^{\prime}, C_{o}\right)$, we obtain that $s_{A}\left(R\left(C_{A}^{\prime \prime}, C_{B}^{\prime}\right)\right)>s_{A}\left(R\left(C_{A}^{\prime}, C_{B}^{\prime}\right)\right)$. But this contradicts that $C_{A}^{\prime}$ is a best response to $C_{B}^{\prime}$. 
Case 2: $W\left(C_{A}^{\prime}, C_{o}\right)>W\left(\hat{C}_{A}, C_{o}\right)$.

(Note that in this case we can not apply Lemma 3.8, since the solution to problem (6.13) may not be feasible.)

By Assumption 2, the slopes of the interest group' indifferent curves evaluated at $\left(\hat{C}_{A}, C_{o}\right)$ are stepper than the slope of the isovote curves evaluated at $\left(\hat{C}_{A}, C_{o}\right)$, we have that $W\left(C_{A}^{\prime}, C_{o}\right)>W\left(\hat{C}_{A}, C_{o}\right)$. This implies that

$$
s_{A}\left(C_{A}^{\prime}, C_{o}\right)<\frac{1}{2}+b
$$

We distinguish two subcases:

Case 2.1: $W\left(C_{o}, C_{B}^{\prime}\right) \geqslant W\left(\hat{C}_{A}, C_{o}\right)$.

Then, by Assumption 2, we have that $s_{B}\left(C_{o}, C_{B}^{\prime}\right)<\frac{1}{2}-b$. This implies that

$$
s_{A}\left(C_{o}, C_{B}^{\prime}\right)>\frac{1}{2}+b .
$$

And since $R\left(C_{A}^{\prime}, C_{B}^{\prime}\right)$ is either $\left\{\left(C_{A}^{\prime}, C_{o}\right)\right\}$ or $\left\{\left(C_{A}^{\prime}, C_{o}\right),\left(C_{o}, C_{B}^{\prime}\right)\right\}$ (note that by Lemma 4.3 and 4.4 in equilibrium neither $\left(C_{o}, C_{o}\right)$ nor $\left(C_{A}^{\prime}, C_{B}^{\prime}\right)$ belongs to $\left.R\left(C_{A}, C_{B}\right)\right)$, then, by $(6.15)$ and $(6.14)$, we have that

$$
s_{A}\left(C_{o}, C_{B}^{\prime}\right)>s_{A}\left(R\left(C_{A}^{\prime}, C_{B}^{\prime}\right)\right) .
$$

Take then, $C_{A}^{\prime \prime}=C_{o}$. And note that $R\left(C_{A}^{\prime \prime}, C_{B}^{\prime}\right)=\left\{\left(C_{o}, C_{B}^{\prime}\right)\right\}$. Consequently and from $(6.16), s_{A}\left(R\left(C_{A}^{\prime \prime}, C_{B}^{\prime}\right)\right)>s_{A}\left(R\left(C_{A}^{\prime}, C_{B}^{\prime}\right)\right)$ and so, $C_{A}^{\prime}$ is not a best response to $C_{B}^{\prime}$ which is a contradiction.

Case 2.2: $W\left(C_{o}, C_{B}^{\prime}\right)<W\left(\hat{C}_{A}, C_{o}\right)$.

It implies that $W\left(C_{o}, C_{B}^{\prime}\right)<W\left(C_{A}^{\prime}, C_{o}\right)$. Consider then, the contract proposal $C_{A}^{\prime \prime}$ where

$$
\begin{aligned}
C_{A}^{\prime \prime} \in & \underset{C_{A}}{\arg \max } s_{A}\left(C_{A}, C_{o}\right) \\
& \text { s.t. } W\left(C_{A}, C_{o}\right) \geqslant W\left(C_{o}, C_{B}^{\prime}\right)+\varepsilon
\end{aligned}
$$

with $\varepsilon>0$ and close enough to 0 . Since $W\left(C_{o}, C_{B}^{\prime}\right)<W\left(\hat{C}_{A}, C_{o}\right)$, by Lemma 3.8 , we know that $C_{A}^{\prime \prime}$ is feasible and $p\left(C_{A}^{\prime \prime}, C_{o}\right)=\pi_{m}$ (and so, $\left.C_{A}^{\prime \prime} \neq C_{A}^{\prime}\right)$. And since $C_{A}^{\prime}$ also satisfies the restriction of the problem (6.17) and $C_{A}^{\prime \prime} \neq C_{A}^{\prime}$, we have that $C_{A}^{\prime}$ does not maximizes $s_{A}$ and so, $s_{A}\left(C_{A}^{\prime \prime}, C_{o}\right)>s_{A}\left(C_{A}^{\prime}, C_{o}\right)$. Finally, since $\varepsilon>0$, we have that $R\left(C_{A}^{\prime \prime}, C_{B}^{\prime}\right)=\left\{\left(C_{A}^{\prime \prime}, C_{o}\right)\right\}$, and so $s_{A}\left(R\left(C_{A}^{\prime \prime}, C_{B}^{\prime}\right)\right)>s_{A}\left(R\left(C_{A}^{\prime}, C_{B}^{\prime}\right)\right)$. 
It implies that $C_{A}^{\prime}$ can not be a best response to $C_{A}^{\prime}$ and it is a contradiction. Q.E.D.

\section{Proof of Theorem 4.6:}

Suppose to the contrary that there is a political equilibrium $\left(C_{A}, C_{B}\right)$ and $\left(C_{A}, C_{B}\right) \neq\left(C_{A}^{*}, C_{B}^{*}\right)$.

Since by Proposition 4.1, the system of equations $S$ has a unique solution, we know that $\left(C_{A}, C_{B}\right)$ can not be a solution to the system $S$. Consequently, we distinguish three cases:

Case 1: $\left(C_{A}, C_{B}\right)$ does not satisfies equation $(3)$ of system $S$. Then, $p\left(C_{A}, C_{o}\right) \neq \pi_{m}$ or $p\left(C_{o}, C_{B}\right) \neq \pi_{m}$.

Case 1.1: $p\left(C_{A}, C_{o}\right) \neq \pi_{m}$ and $p\left(C_{o}, C_{B}\right) \neq \pi_{m}$.

Then, by Lemmas 4.3 and 4.4 , we have that $\left(C_{o}, C_{o}\right) \notin R\left(C_{A}, C_{B}\right)$ and $\left(C_{A}, C_{B}\right) \notin R\left(C_{A}, C_{B}\right)$. And by Lemma 4.5 , we have that $\left(C_{A}, C_{o}\right) \notin R\left(C_{A}, C_{B}\right)$ and $\left(C_{o}, C_{B}\right) \notin R\left(C_{A}, C_{B}\right)$. Consequently, $R\left(C_{A}, C_{B}\right)=\emptyset$ which is a contradiction.

Case 1.2: $p\left(C_{A}, C_{o}\right) \neq \pi_{m}$ and $p\left(C_{o}, C_{B}\right)=\pi_{m}$.

Then, by Lemmas $4.3,4.4$ and 4.5 , we have that $R\left(C_{A}, C_{B}\right)=\left\{\left(C_{o}, C_{B}\right)\right\}$. This implies that $W\left(C_{o}, C_{B}\right)>\max \left\{W\left(C_{A}, C_{o}\right), W\left(C_{o}, C_{o}\right)\right\}$.

Since $p\left(C_{o}, C_{B}\right)=\pi_{m}$ is continuous in $c_{B}$ and $p_{B}$, there is $C_{B}^{\prime}=\left(c_{B}^{\prime}, p_{B}^{\prime}\right)$ such that $p\left(C_{o}, C_{B}^{\prime}\right)=\pi_{m}$ and

$$
W\left(C_{o}, C_{B}\right)>W\left(C_{o}, C_{B}^{\prime}\right)>\max \left\{W\left(C_{A}, C_{o}\right), W\left(C_{o}, C_{o}\right)\right\} .
$$

By Assumption 2, in $\left(c_{B}, p_{B}\right)$ the slope of the function $p\left(C_{o}, C_{B}\right)=\pi_{m}$ is strictly positive. Then, from (6.18), we compare $C_{B}$ and $C_{B}^{\prime}$ and we have that $c_{B}^{\prime}>c_{B}$ and $p_{B}^{\prime}>p_{B}$. Thus, since the function $s_{B}$ is strictly increasing in $c_{B}$ and $p_{B}$,

$$
s_{B}\left(C_{o}, C_{B}^{\prime}\right)>s_{B}\left(C_{o}, C_{B}\right) .
$$

Finally, from (6.18) and the fact that $p\left(C_{o}, C_{B}^{\prime}\right)=\pi_{m}$, we know that $R\left(C_{A}, C_{B}^{\prime}\right)=$ $\left\{\left(C_{o}, C_{B}^{\prime}\right)\right\}$. Hence, by $(6.19), C_{B}$ can not be a best response to $C_{A}$, which is a contradiction.

Case 1.3: $p\left(C_{A}, C_{o}\right)=\pi_{m}$ and $p\left(C_{o}, C_{B}\right) \neq \pi_{m}$.

Then, by the same argument as in Case 1.2, now in terms of party $A$, we reach a contradiction.

Consequently, $\left(C_{A}, C_{B}\right)$ must satisfy equation (3) of system $S$.

Case 2: $\left(C_{A}, C_{B}\right)$ does not satisfy equation (1) of system $S$. 
Then, either $W\left(C_{A}, C_{o}\right)>W\left(C_{o}, C_{B}\right)$ or $W\left(C_{A}, C_{o}\right)<W\left(C_{o}, C_{B}\right)$ which by Lemmas 4.3 and 4.4 , implies that $R\left(C_{A}, C_{B}\right)=\left\{\left(C_{A}, C_{o}\right)\right\}$ for the first case, and $R\left(C_{A}, C_{B}\right)=\left\{\left(C_{o}, C_{B}\right)\right\}$ for the second case.

Suppose first that $R\left(C_{A}, C_{B}\right)=\left\{\left(C_{o}, C_{B}\right)\right\}$, i.e., $W\left(C_{A}, C_{o}\right)<W\left(C_{o}, C_{B}\right)$.

In the above Case 1 , we already showed that $p\left(C_{o}, C_{B}\right)=\pi_{m}$. Then, the same argument as in Case 1.2 can be used to obtain a contradiction.

Suppose second that $R\left(C_{A}, C_{B}\right)=\left\{\left(C_{A}, C_{o}\right)\right\}$.

This case is similar to the one in Case 1.3, and so, using the same argument as in 1.3 , we reach a contradiction.

Consequently, $\left(C_{A}, C_{B}\right)$ satisfies equation (1) of system $S$ so that $W\left(C_{A}, C_{o}\right)=$ $W\left(C_{o}, C_{B}\right)$. This equality and Lemmas 4.3 and 4.4 imply that

$$
R\left(C_{A}, C_{B}\right)=\left\{\left(C_{A}, C_{o}\right),\left(C_{o}, C_{B}\right)\right\}
$$

In Case 3, we take into account expression (6.20).

Case 3: $\left(C_{A}, C_{B}\right)$ does not satisfy equation (2) of system $S$.

Then, either $s_{A}\left(C_{A}, C_{o}\right)>s_{A}\left(C_{o}, C_{B}\right)$ or $s_{A}\left(C_{A}, C_{o}\right)<s_{A}\left(C_{o}, C_{B}\right)$

Suppose first that $s_{A}\left(C_{A}, C_{o}\right)>s_{A}\left(C_{o}, C_{B}\right)$.

Since the function $W$ is continuous in $c_{j}$ and by Assumption $2, \frac{\partial W}{\partial c_{j}}<0$, we can define a contract proposal $C_{A}^{\prime}=\left(c_{A}^{\prime}, p_{A}^{\prime}\right)$ where $c_{A}^{\prime}<c_{A}, p_{A}^{\prime}=p_{A}$ and

$$
W\left(C_{A}^{\prime}, C_{o}\right)=W\left(C_{o}, C_{B}\right)+\varepsilon
$$

(where $\varepsilon>0$ and close enough to 0 ).

Since, from Case 1 , we know that $p\left(C_{o}, C_{B}\right)=\pi_{m}$, we have $\left(C_{A}^{\prime}, C_{B}\right) \notin$ $R\left(C_{A}^{\prime}, C_{B}\right)$. Moreover, for $\varepsilon$ sufficiently small, $\left(C_{o}, C_{o}\right) \notin R\left(C_{A}^{\prime}, C_{B}\right)$. Then, by (6.20) and (6.21) we obtain that $R\left(C_{A}^{\prime}, C_{B}\right)=\left\{\left(C_{A}^{\prime}, C_{o}\right)\right\}$ and so, $s_{A}\left(R\left(C_{A}^{\prime}, C_{B}\right)\right)>$ $s_{A}\left(R\left(C_{A}, C_{B}\right)\right)$. Consequently, $C_{A}$ is not a best response to $C_{B}$, which is a contradiction.

Suppose second that $s_{A}\left(C_{A}, C_{o}\right)<s_{A}\left(C_{o}, C_{B}\right)$.

Consider then, the contract proposal $C_{A}^{\prime}=C_{o}$. By (6.20), we have $R\left(C_{A}^{\prime}, C_{B}\right)=$ $\left\{\left(C_{o}, C_{B}\right)\right\}$ and so, $s_{A}\left(R\left(C_{A}^{\prime}, C_{B}\right)\right)>s_{A}\left(R\left(C_{A}, C_{B}\right)\right)$. Consequently, $C_{A}$ is not a best response to $C_{B}$, which is a contradiction. Q.E.D. 


\section{References}

- A. Alesina and H. Rosenthal (1995), "Partisan Politics, Divided Government and the Economy", New York: Cambridge University Press, Cambridge.

- A. Alesina and H. Rosenthal (1996), "A Theory of Divided Government", Econometrica, 64, 1311-1341.

- D. Austen-Smith (1989), "Sincere Voting in Models of Legislative Elections", Social Choice and Welfare, 6, 287-299.

- D. Austen-Smith and J. Banks (1988), "Elections, Coalitions and Legislative Outcomes", American Political Science Review, 82, 405-422.

- D. P. Baron (1994), "Electoral Competition With Informed and Uninformed Voters", American Political Science Review, 88, 33-47.

- B. D. Bernheim and M. D. Whinston (1986), "Menu Auctions, Resource Allocation and Economic Influence", Quarterly Journal of Economics, 101, 1-31.

- A. Gerber and I. Ortuño-Ortín (1998), "Political Compromise and Endogenous Formation of Coalitions", Social Choice and Welfare, 15, 445-454.

- G. M. Grossman and E. Helpman (1994), "Protection for Sale", American Economic Review, 84, 833-850.

- G. M. Grossman and E. Helpman (1996a), "Electoral Competition and Special Interest Politics", Review of Economic Studies, 63, 265-286.

- G. M. Grossman and E. Helpman (1996b), "Electoral Competition with Policy Compromise" The Forder Institute For Economic Research, working paper n. 1096. Tel-Aviv University.

- L. L. Langbein (1993), "PACs, lobbies and political conflict: The case of gun control", Public Choice, 77, 551-572.

- I. Ortuño-Ortín (1997), "A Spatial Model of Political Competition and Proportional Representation", Social Choice and Welfare, 14, 427-438.

- K. T. Poole and T. Romer (1985), "Patterns of PAC contributions to the 1980 campaigns for the U.S. House of Representatives", Public Choice, 47, 63-111.

- J. Potters and R. Sloof (1996), "Interest Groups: A Survey of Empirical Models that Try to Assess Their Influence", European Journal of Political Economy, 12, 403-442.

- J. Potters and F. van Winden F. v. (1995), "Models of Interest Groups: Four Different Approaches", In: N. Schofield, ed., Social Choice and Political Economy (Kluwer, Boston, MA).

- K. Schozman and J. Tierney (1986), "Organized interests in American democracy", Harper and Row, New York. 